\title{
ZERO/MINIMUM TURNING RADIUS OF A TRACTOR
}

\author{
Sumair Sunny ${ }^{1}$, Sunny Pawar $^{2}$, Siddhesh Ozarkar ${ }^{3}$ \\ ${ }^{1}$ Mechanical Engineer, Maharashtra Institute of Technology, Maharashtra, India \\ ${ }^{2}$ Mechanical Engineer, Maharashtra Institute of Technology, Maharashtra, India \\ ${ }^{3}$ Mechanical Engineer, Maharashtra Institute of Technology, Maharashtra, India
}

\begin{abstract}
In this paper we have taken a conventional tractor and endowed it with the ability to take turns with a much smaller turning radius. The paper comprehensively covers the methodology, calculations, analysis and concludes with a value proposition. The base-line tractor we have considered is the John Deere 5065 E model. We try to achieve our goal without over complicating the original design. At the same time the solution needs to be realistic and technically feasible whilst also cost effective. We also try to facilitate poke-yoke and fail-safe measures so as to help users adjust to the new design.
\end{abstract}

Keywords: Zero Turning, Hydrostatic Transmission, Simulink, Tractor, Steering, Hydraulics

\section{WHAT IS ZERO/MINIMUM TURNING?}

A zero turn if taken literally means that the tractor should be able to rotate about a stationary pivot point/axis. A minimum turn radius means that the turn envelope of the tractor should be as small as could possibly be achieved. In other words the minimum wall to wall distance within which the vehicle can turn should be as small as possible.

\subsection{Base-Line Tractor's Specifications [11]:}

- $\quad$ Engine max. power: 65hp @ 2400 rpm

- $\quad$ Steering type: power steering

- Front tire width: 6.5 inch

- Front tire outer diameter: 25 inch

- Rear tire width: 18.4 inch

- Rear tire outer diameter: 50 inch

- Total Weight: $2290 \mathrm{~kg}$

- Wheel Base: $2035 \mathrm{~mm}$

- Overall length: $3535 \mathrm{~mm}$

- $\quad$ Overall width: $1890 \mathrm{~mm}$

- $\quad$ Turning Radius with brakes: 3099 mm

\subsection{Prerequisite Knowledge}

Tractors take sharp turns with brake assistance. That means if a tractor is to turn left the driver can press the left brake to reduce the speed of the left drive wheel while the right wheel continues to move undisturbed. The same can be done for right turns. This independent braking system enables the tractor to take sharp turns.

Our aim would be to try and reduce this turning radius as far as possible.

Since the tractor has a power steering system, we do not want to eliminate this feature unless we are implementing a better steering option.
We have assumed the peripheral diameter of both tires since this data wasn't available on John Deere's website. For the front tire we have considered a peripheral diameter of 25 " and for the rear 50".

We have also considered the weight distribution about the center of gravity to be in a 40/60 ratio. In other words, $40 \%$ of the weight acts on the front axle $\& 60 \%$ of the weight acts on the rear axle.

\section{SOLUTION}

The means by which we wish to achieve our goal is by the extensive use of hydraulics. Please refer to the diagram on following page. [2]

In our design we eliminate the gear box transmission \& differential of the tractor as well as its conventional braking system by incorporating both of these systems in the hydraulic circuit. The reason for doing this is due to the fact that the two independent hydraulic motors enable the wheels to rotate not only in the same direction (for forward or reverse) but also in opposite direction (for zero turning). This is analogous with the way an army tank turns. This solution is similar to the John Deere "Skid Steer" however we try to eliminate the "skid" as in some cases it may induce heavy stresses onto the drive axles. 


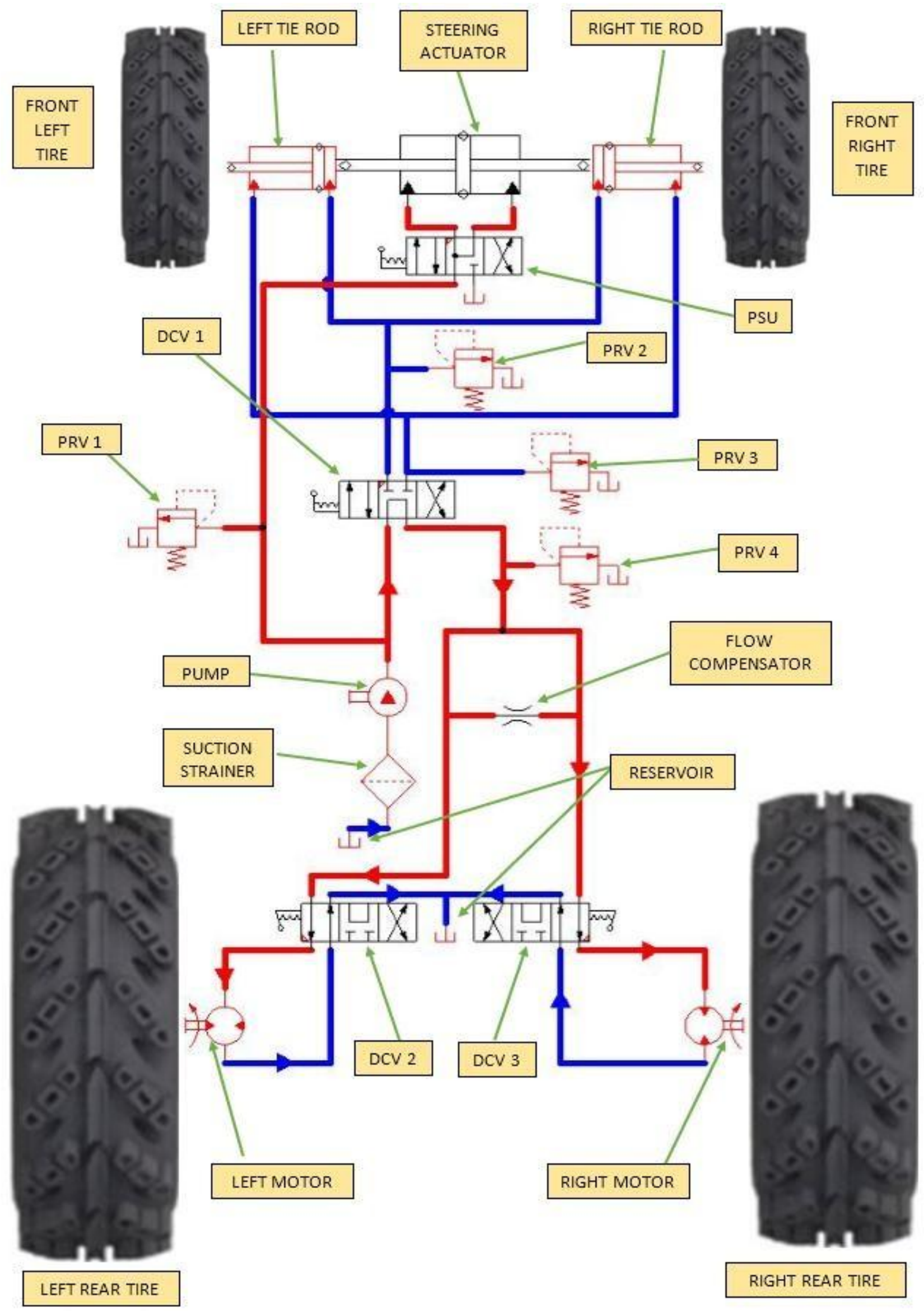

Fig -1: Overview of Hydraulic Circuit 
In this design, regular steering is achieved by means of the power steering unit. We do not intend to change the power steering that is already present, however we do wish to introduce hydraulic tie-rods connecting the ends of the steering rods to the ends of the steering arms. Thus in our design we have also calculated the power and pressure required for hydraulic steering unit. The force on the steering rod will also be the force that the tie rods will be subjected to, considering the same pressure in both the tierods as well as the double acting steering rod.

The engine (prime mover) is connected rigidly to a heavy duty axial piston pump. The pump receives fluid from the reservoir via a suction strainer. The fluid is pressurized to 4500 PSI. This fluid gets split, such that some of it goes to the steering unit. The rest is used either for the zero turning tie rods or the Hydrostatic transmission, (both of which are never to be actuated simultaneously).

The pressure in the steering circuit as well as the zero turn tie rod's circuit, is limited to 1000 PSI, whereas the pressure in the HST circuit is 4500 PSI. Thus 4 pressure relief valves must be used so as to enable the use of multiple pressures.

The pump is a heavy duty axial piston pump selected from an Eaton catalog. Its details are provided in the coming section. The motors are also axial piston heavy duty types.

DCV - Direction Control Valve - These are provided in order to change or reverse the direction of flow of fluid in the circuit.

DCV 1: This prevents the simultaneous operation of the drive wheels and the extension of the turn tie rods into zero turn position. It helps extend and retract the tie rods. When it is in center position the rods get hydraulically locked and all the fluid being pumped is directed towards the drive wheel motors.

DCV 2 \& 3: These DCVs control the direction in which the motors rotate (forward $\&$ reverse) and can also be used for braking purposes (in the center position).

PRV - Pressure Relief Valve - These are used to maintain the correct pressure in the circuit. There are four PRVs in the circuit. This is due to the fact that the steering and zero turning circuits uses 1000 PSI whereas, the HST uses 4500 PSI. Correct pressure must be supplied in order for efficient performance and to prevent damage of components.

Since the pump pressurizes the fluid to 4500 PSI, PRV 1, 2 \& 3 limits the pressure to 1000 PSI. PRV 4 only comes into use if the pressure exceeds 4500 PSI and maintains this pressure being supplied to the motors.

PSU - Power Steering Unit- This is a component that already exists in the baseline vehicle however since its data isn't provided we needed to provide some calculations to represent the steering unit. The PSU in the above circuit is being represented by a DCV however it should not be mistaken for an actual DCV. A more detailed explanation of this device is provided in coming section. The PSU is connected to the double actuating cylinder which is used for regular steering conditions.

The double acting cylinder is attached to the hydraulic tie rods. When these actuate we get the zero turning position of the front wheels.

Flow compensator - This device behaves analogous to a differential. When less flow is required in one tire and more in the other during turning it increases the flow to one motor and compensates the same amount from the other.

\subsection{Regular Turning}

The regular turning of the tractor can be achieved with the power steering unit. The variation in speed and torque required by the wheels on the inside and outside of the turn can be assisted with the flow compensator.

For tight turns, normally a tractor can brake one wheel. So as to not eliminate this feature of its maneuverability the DCVs $2 \& 3$ are provided with a center position in which the fluid can directly return to the reservoir and at the same time the driving motor can be stalled thus seizing the corresponding wheel.

For example for a tight left turn, the left motor's DCV (DCV 2) is put into hydraulic locking position, whereas the right motor's DCV (DCV 3) is left in forward position. For tight right turns vice-versa. 


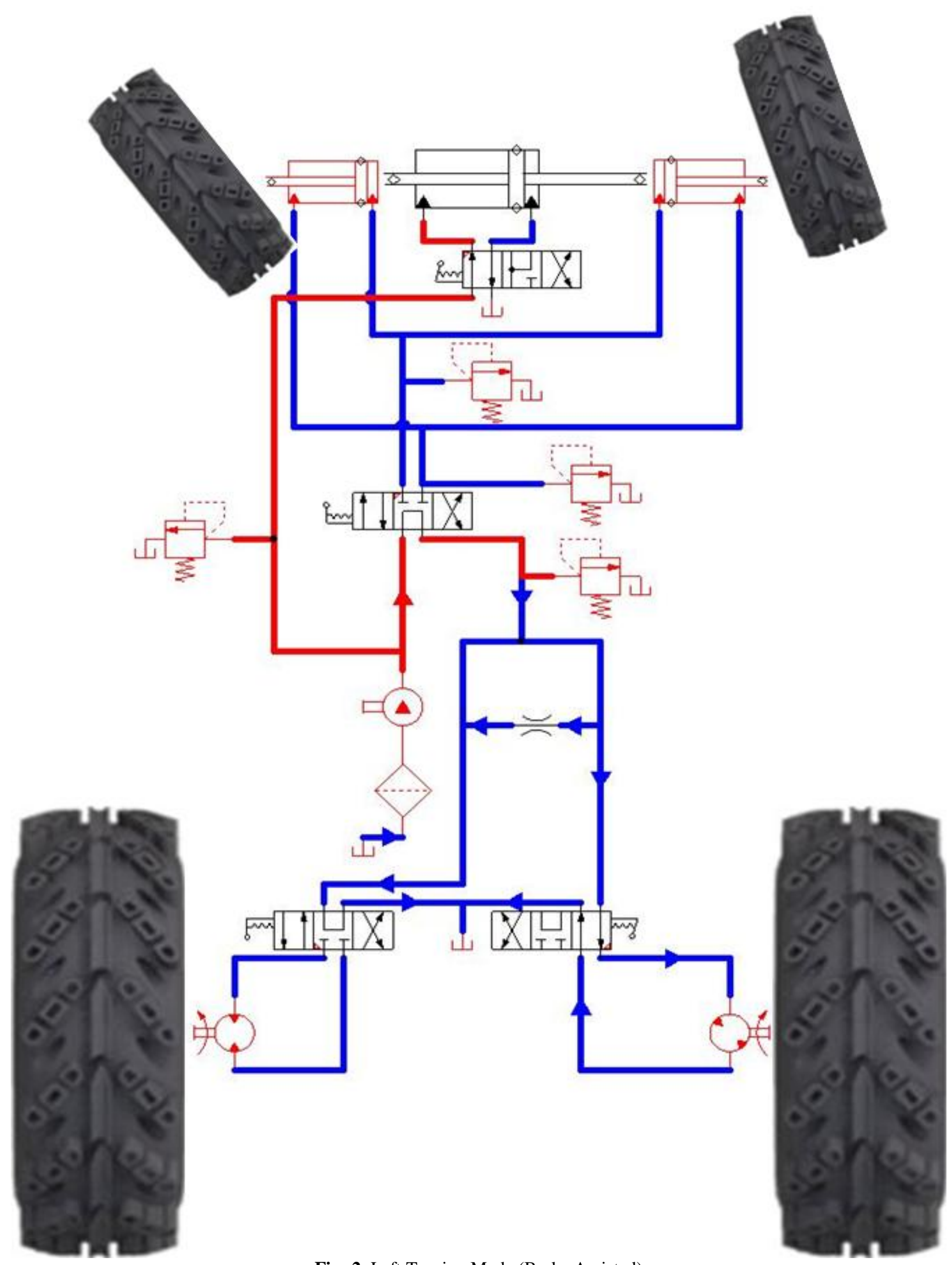

Fig -2: Left Turning Mode (Brake Assisted) 


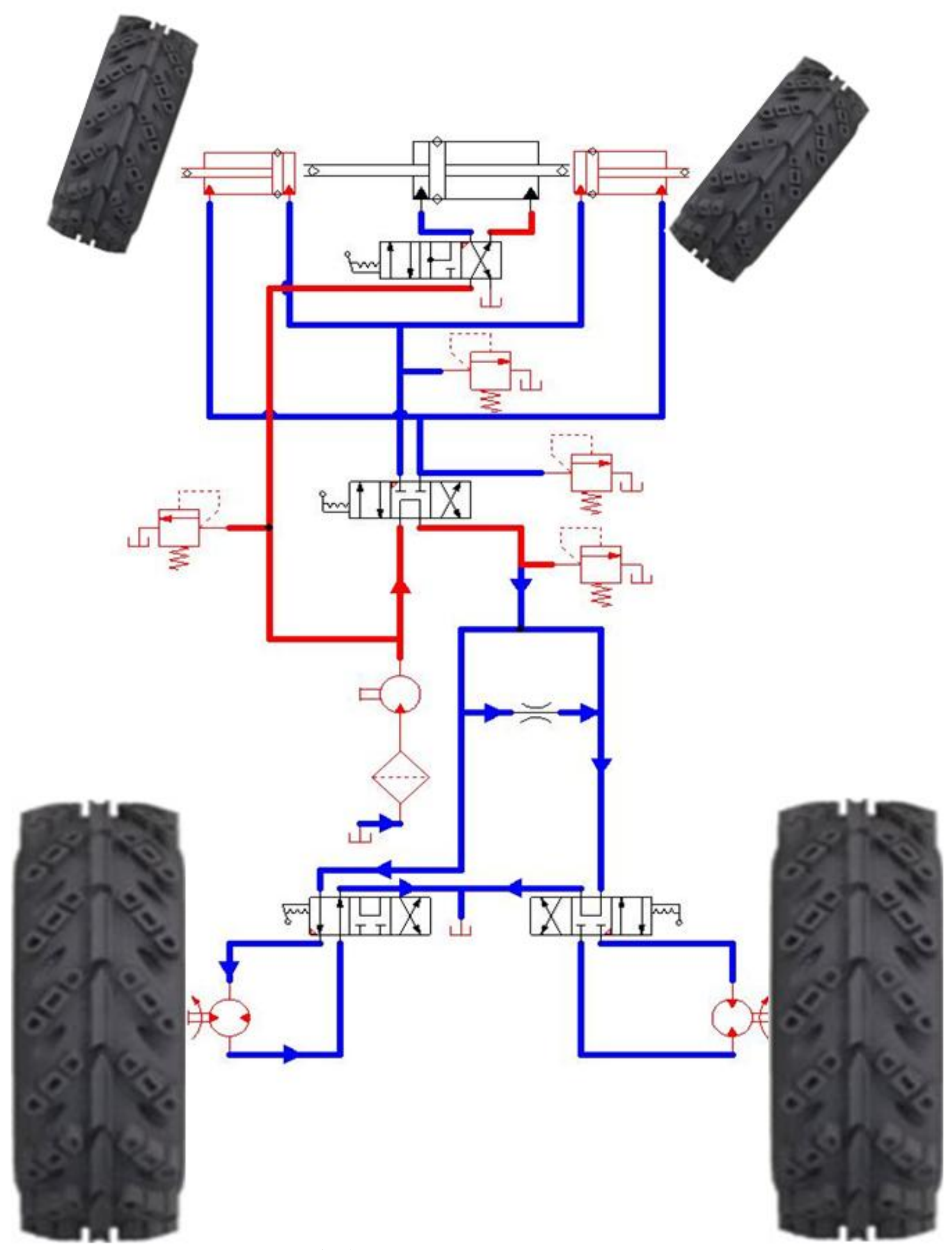

Fig -3: Right Turning Mode (Brake Assisted) 


\subsection{Zero Turning Mode:}

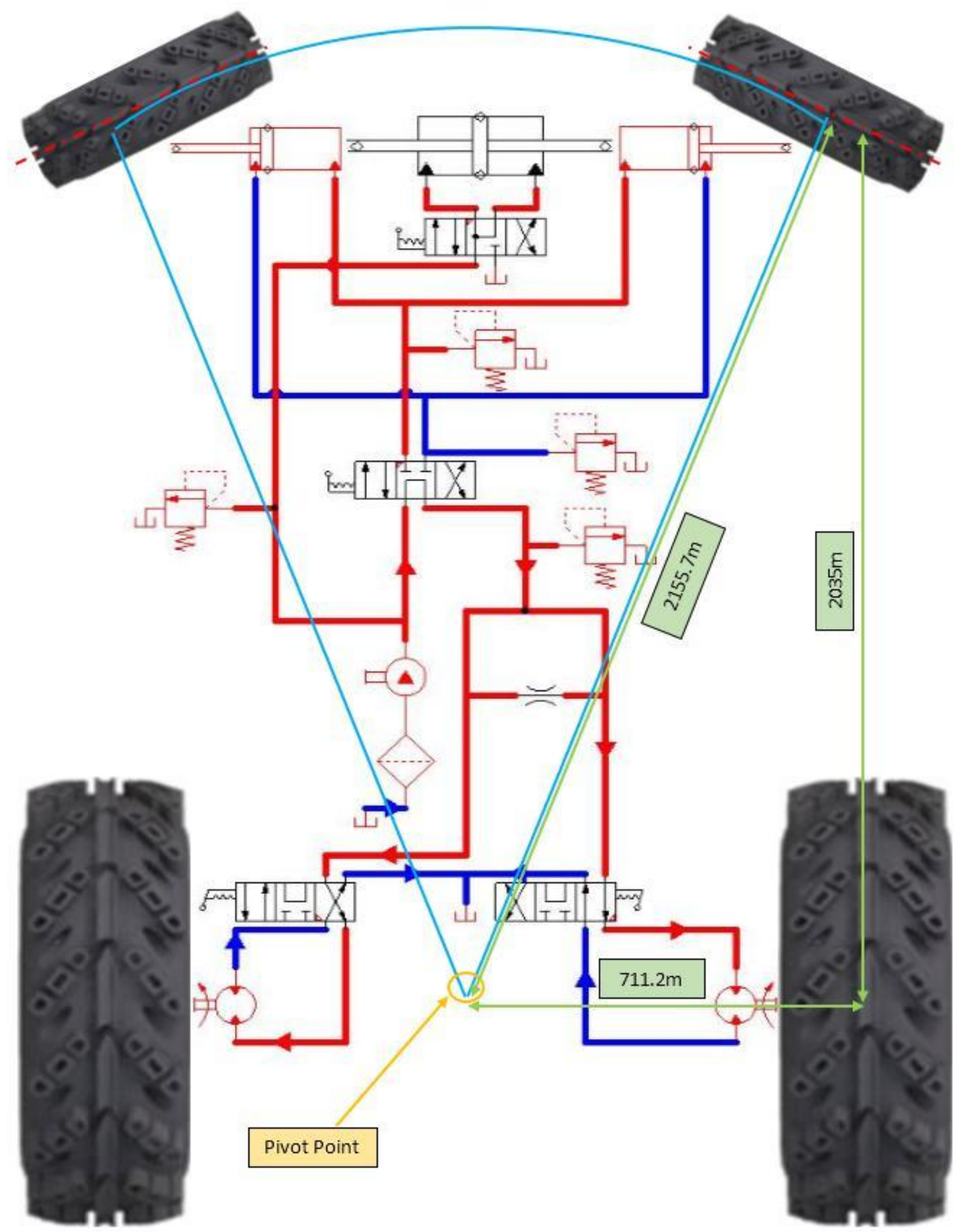

Fig -4: Zero Turning Mode 
When a zero turn is required, both the cylinders can be made to extend simultaneously. The steering wheel is brought into center position.

Thus the line drawn through the center of the wheel in the top view forms a tangent to an arc whose center coincides with the vehicles center (exactly between rear wheels).

As the rear tires rotate in opposite directions, the tractor will be able to rotate about its center hence achieving a zero turn. The main drawback is that this circuit is complex to design. Also more components means less reliability and increased cost.

If we consider the pivot point as the center of the turn, then ideally the tractor would turn exactly about this point, thus successfully achieving a zero turn. Considering the wheel base and half the wheel track the hypotenuse would form radius to the turn envelope. This would help us understand the amount of room required for the tractor to take a zero turn.

\section{NOTE:}

1. When the tie rods expand and retract the drive wheels need to be stationary.

2. When the tie rods have expanded the drive wheels should rotate in opposite directions. In order to achieve a zero turn.

If the above two conditions are not satisfied there will be immense stresses on the front wheels' axles. Thus some fool proofing may be required with the help of electronics (logic gates, etc.). As a fail-safe to the first condition if both the motors as well as the hydraulic tie rods are actuated simultaneously the power demand will exceed what is provided by the engine thus, stalling the circuit before immense forces are experienced.

\section{HYDRAULIC STEERING DESIGN}

\subsection{Approximate Kingpin Torque}

[10] We have assumed a 40/60 weight distribution, (i.e. $40 \%$ of the weight supported by front axle and $60 \%$ by rear).

Total weight of the tractor $=2290 \mathrm{~kg}$

Therefore weight on the steering axle $=40 \% * 2290 \mathrm{~kg}=$ $916 \mathrm{~kg}$ (or $2019.78 \mathrm{lbs}$ )

Next we must determine the steering geometry:

Let $\mathrm{E}$ be the Kingpin Eccentricity $=6.5$ inch

Let $\mathrm{B}$ be the tire tread width $=6.5$ inch (front tires)

Hence we get an $\mathrm{E} / \mathrm{B}$ ratio of 1

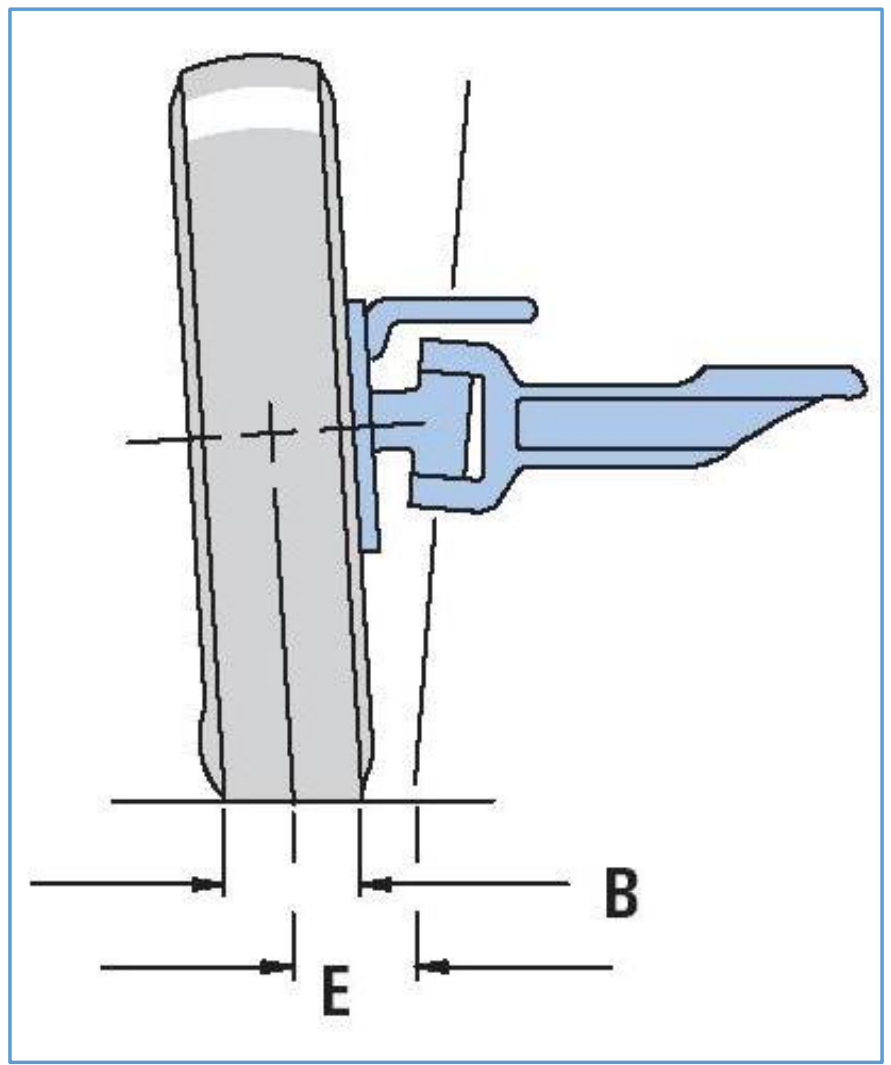

Fig -5: Kingpin and Tire Width (Sourced from Char Lynn Hydraulic Steering Catalog, [8])

Now from the chart of coefficient of friction vs. E/B ratio we can determine the coefficient of friction.

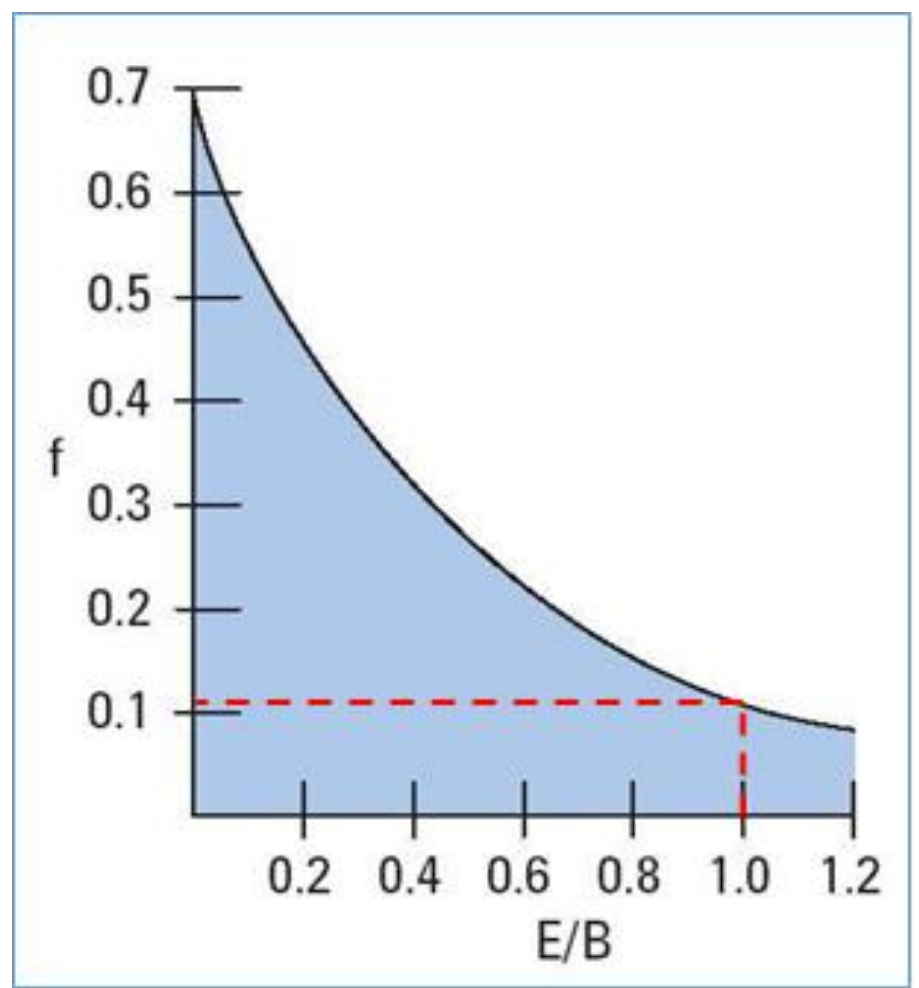

Graph -1: Coefficient of friction v/s E/B ratio (Sourced from Char Lynn Hydraulic Steering Catalog, [8]) 


\section{Method:}

Once you know your E/B ratio draw a vertical line from the $\mathrm{x}$ axis until it intersects with the curve. From the point of intersection, draw a horizontal line to intersect the $y$ axis and note the value of coefficient of friction (f).

In our case since our E/B ratio is 1, the corresponding coefficient of friction is 0.11 approximately.

Total kingpin torque:

$$
T=w * f * \sqrt{\frac{B^{2}}{8}+E^{2}}
$$

Where,

$\mathrm{T}=$ total kingpin torque required to steer axle (lb-in)

$\mathrm{w}=$ weight supported by steered axle (lbs.)

$\mathrm{f}=$ coefficient of friction

$\mathrm{B}=$ tire tread width (in)

$\mathrm{E}=$ kingpin Eccentricity (in)

$\therefore T=2019.78 * 0.11 * \sqrt{\frac{6.5^{2}}{8}+6.5^{2}}$

$\therefore \mathrm{T}=1531.745 \mathrm{lb}$-in $($ or $173.09 \mathrm{Nm})$

\subsection{Approximate Cylinder Force (CF):}

$$
C F=\frac{T}{R}
$$

Where,

$\mathrm{T}=$ total kingpin torque required to steer axle: $1531.745 \mathrm{lb}-$ in

$\mathrm{R}=$ Steering Arm Radius: 2.5 inch (63.5mm) assumed

$\therefore C F=\frac{1531.745}{2.5}$

$\therefore \mathrm{CF}=612.69 \mathrm{lbs}($ or $2726 \mathrm{~N})$

\subsection{How a PSU Works:}

A PSU in generally seen to have 4 ports (T, P, L \& R). This stands for:

$\mathrm{T}=$ Tank $=$ flow return to the reservoir from this port.

$\mathrm{P}=$ Pump $=$ pressurized flow enters the PSU from the pump.

L \& R = Left and Right = in these ports, generally the flow can be in either direction depending on the direction in which the steering wheel is rotated. The direction of the flow can control the way in which the vehicle is turned (either left turn or right turn)

The connections should be such that, from a user's perspective when the steering wheel rotates clockwise the vehicle turns right and vice-versa.
The benefit of power steering is that the power generally comes from the pump in the form of high pressure fluid. The human (user) only needs to provide the direction.

This is beneficial in situations where the amount of force required to steer may vary immensely. Also since the tractor is normally used for off-road applications, it would be difficult to predict the exact coefficient of friction the vehicle would be subjected to. Considering worst case scenarios we must make sure that the user is in control at all time. The user should be able to steer the vehicle easily and effortlessly.

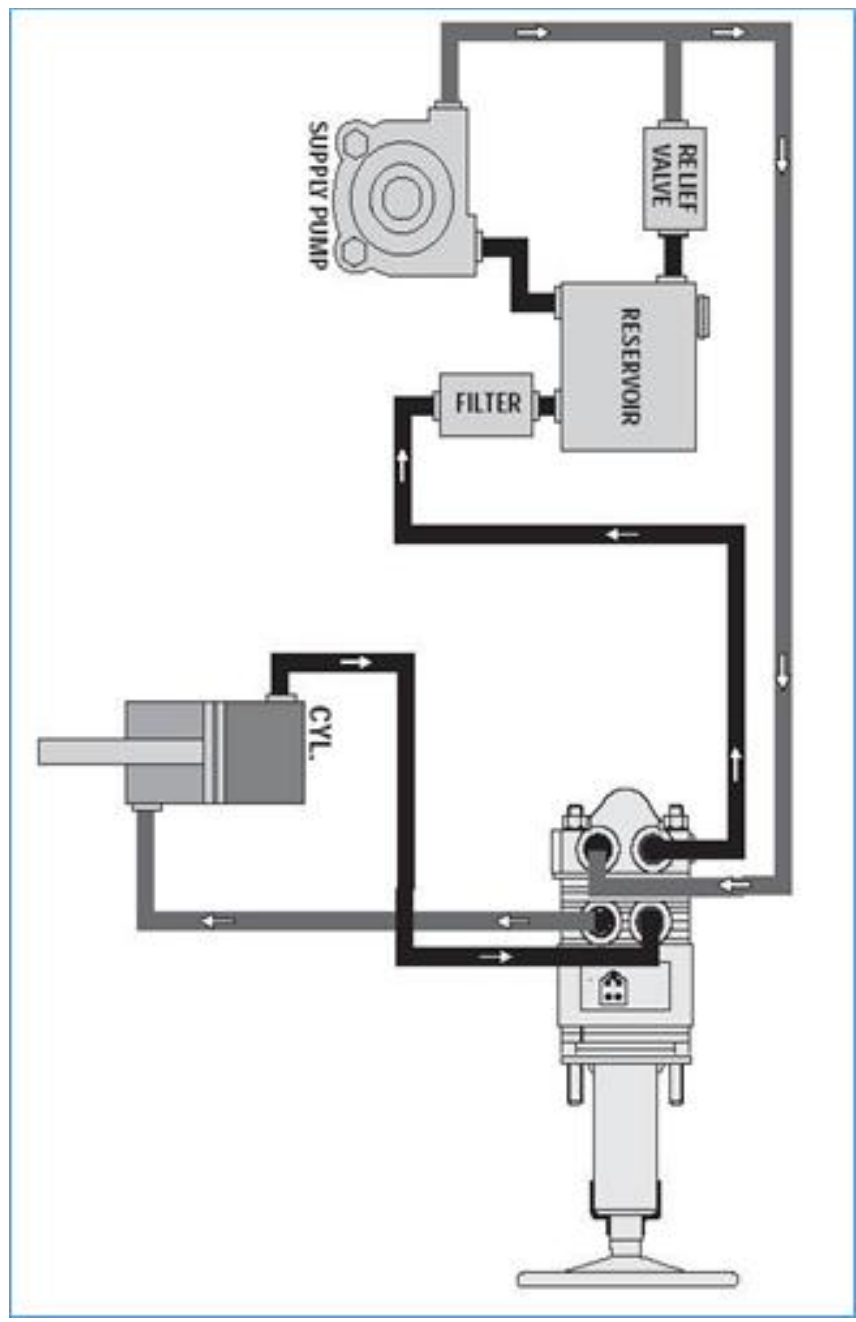

Fig -6: [9] PSU circuit arrangement (Sourced from Hydraguide ${ }^{\mathrm{TM}}$ Series Hydrostatic Steering Units Catalog)

We have selected a Char-Lynn Series 2 PSU. Thus we can operate the Steering system at a pressure of 1000 PSI (or 68.966 bar). 


\subsection{Design of Linear Actuators:}

$$
\begin{gathered}
\text { Piston Area }=\frac{\text { Cylinder Force }}{\text { Cylinder Pressure }} \\
\therefore \text { Piston Area }=\frac{612.698 \mathrm{lbs}}{1000 \mathrm{PSI}}
\end{gathered}
$$$$
\therefore \text { Piston Area }=0.613 \mathrm{in}^{2}\left(\text { or } 395.29 \mathrm{~mm}^{2}\right)
$$

We notice in the steering, there are two different linear actuators:

1. The double acting cylinder for regular steering

2. The hydraulic tie rod for zero turning operations

We shall design these actuators as per our requirements and also try to model them similar to products that are commercially available.

The main stress bearing element in these actuators which can be subject to buckling is the cylinder rod. For both, the double acting steering actuator as well as the tie rods we shall design the cylinder and rods out of same material.

[7] For both the actuators we shall perform a stress based analysis on Ms Excel to check permissibility as well as a strength based analysis on Altair Hypermesh to check for maximum deflection. In both actuators the rod will be subjected to the maximum cylinder force being applied which is $2726 \mathrm{~N}$

The material we have selected is Carbon Steel C40 (hardened and tempered)

This material has an ultimate tensile stress $($ Sut $)=750$ $\mathrm{N} / \mathrm{mm}^{2}$

We are considering a Factor of Safety $(\mathrm{FOS})=5$

\section{Stress Based Analysis:}

Let $\sigma_{\text {per }}$ be the permissible stress that the rod can take.

$$
\begin{gathered}
\text { oper }=\frac{\text { Sut }}{\text { FOS }} \\
\therefore \text { oper }=\frac{750}{5} \\
\therefore \text { oper }=150 \mathrm{~N} / \mathrm{mm}^{2}
\end{gathered}
$$

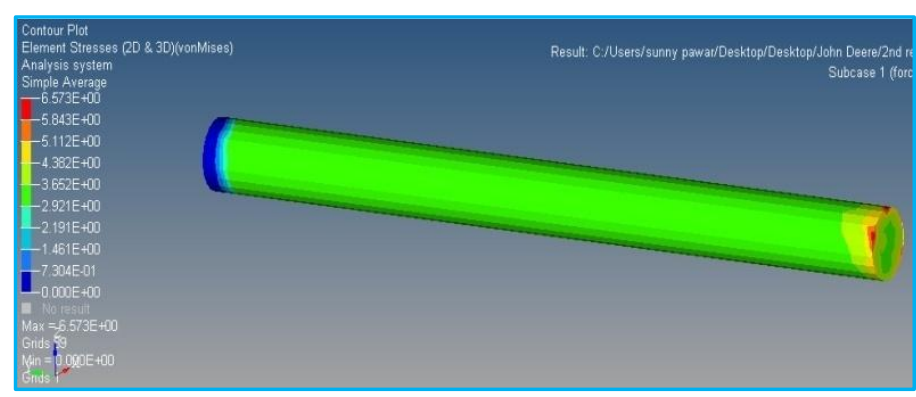

Fig -7: Strength Based Analysis of the Steering Actuator Rod (Maximum Stress: $6.573 \mathrm{~N} / \mathrm{mm}^{2}$ )

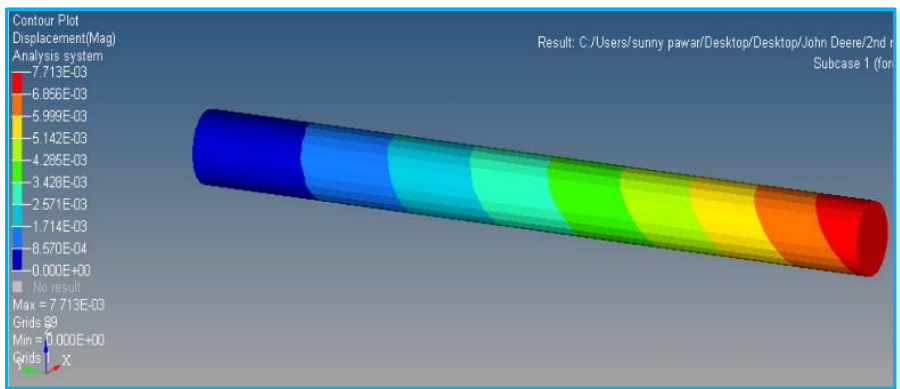

Fig -8: Strength Based Analysis of the Steering Actuator Rod (Maximum Deflection: $7.713 \times 10^{-3} \mathrm{~mm}$ )

Since the maximum stress induced in the $\operatorname{rod}\left(6.573 \mathrm{~N} / \mathrm{mm}^{2}\right)$ is less than the permissible stress $\left(150 \mathrm{~N} / \mathrm{mm}^{2}\right)$, design is safe.

The deflection found from the strength based analysis shows that the rod is subjected to a deflection to the order of $10^{-3}$ $\mathrm{mm}$ which is negligible.

\subsection{Rod \& Cylinder Diameter:}

$$
\begin{gathered}
\text { Area of rod }=\frac{C F}{\sigma p e r} \\
\therefore \text { Area of rod }=\frac{2726}{150}
\end{gathered}
$$

$\therefore$ Area of rod $=18.172 \mathrm{~mm}^{2}$

$\therefore$ Diameter of rod $=4.810 \mathrm{~mm}$ (minimum required)

Nominal rod diameters of linear actuators that are commercially available are 0.63 inch.

$\therefore$ Actual diameter of rod $=0.63$ inch $($ or $16 \mathrm{~mm}$ )

Since this is greater than the nominal required diameter it is PERMISSIBLE.

We shall now proceed with the steering calculations and once this is done, we shall do the calculations for the Zero turn tie rods.

We have assumed the front wheels have a wheel track of 56 inch.

Using Solid Works we can geometrically select a Double acting cylinder with a stroke length of 6 inch (or $152.4 \mathrm{~mm}$ ).

$$
\text { Piston Area }=\frac{\pi}{4} *\left(D^{2}-d^{2}\right)
$$

Where,

$\mathrm{D}=$ bore diameter of the cylinder

$\mathrm{d}=$ rod diameter $=0.63$ inch

Piston Area $=0.613$ inch

$\therefore \mathrm{D}=1.085$ inch 


\subsection{Swept Volume (SV) (from center position to full}

left or right):

$$
\begin{gathered}
\mathrm{SV}=\text { Stroke length } * \text { Piston Area } \\
\mathrm{SV}=6 * 0.613 \\
\mathrm{SV}=3.678 \mathrm{in}^{3}
\end{gathered}
$$

\subsection{Number of turns of Steering Wheel from Lock}

\section{to Lock:}

These means how many revolutions of the steering wheel will be required to turn the front wheels from full left turn position to a full right turn position or vice-versa.

$$
\text { Ideal Displacement }=\frac{\mathrm{SV} \text { (full left to full right) }}{\text { ideal number ofturns }}
$$

Let the ideal number of turns of steering wheel (from full left to full right position) be 2 .

$$
\begin{gathered}
\therefore \text { Ideal Displacement }=\frac{2 * 3.678}{2} \\
\therefore \text { Ideal Displacement }=3.678 \mathrm{in}^{3} / \mathrm{rev}
\end{gathered}
$$

From the Series 2 catalogue selecting the closest possible match we get $3.8 \mathrm{in}^{3} / \mathrm{rev}$

$$
\begin{gathered}
\text { Actual number of turns }=\frac{\mathrm{SV} \text { (full left to full right) }}{\text { actual displacement }} \\
\therefore \text { Actual number of turns }=\frac{2 * 3.678}{3.8}
\end{gathered}
$$

$\therefore$ Actual number of turns $=1.93$ Revolutions (lock to lock)

\section{NOTE:}

We notice that the steering sensitivity is directly related to the displacement of the PSU being used. In case the sensitivity is too much another option from the Char-Lynn series 2 PSUs is $3.1 \mathrm{in}^{3} / \mathrm{rev}$.

\subsection{Pump Flow Required By PSU:}

Flow Required

$=\frac{\text { Actual Displacement } * \text { Actual Number of Turns } * 60}{231}$

$\therefore$ Flow Required $=\frac{3.8 * 1.93 * 60}{231}$

$\therefore$ Flow Required $=1.91$ gpm (or 7.2282 litre $)$

\subsection{Power Demand by PSU:}

Power Demand by PSU $=\frac{\text { Flow } * \text { pressure }}{1714}$

$\therefore$ Power Demand by PSU $=\frac{1.91 * 1000}{1714}$

$\therefore$ Power Demand by PSU $=1.11 \mathrm{hp}($ or $0.8308 \mathrm{~kW})$

\section{ZERO TURN HYDRAULIC TIE ROD DESIGN}

Given on the following page is a line diagram showing Zero Turning Geometry. [3]

From this diagram we gather that the wheels will have to rotate by almost 750 in order to achieve zero turning mode.

The rotation is achieved with the help of hydraulic linear actuators or simply hydraulic tie rods.

We have considered a wheel track of 56" for the front wheels with a King Pin eccentricity of 6.5 " on either side, thus the King Pin to King Pin distance is 43".

The purpose of this image is to comprehend what the stroke length of the hydraulic tie rods should be. Given that the length comes out as 12.427 " the stroke will be half of this: 6.21 " considering next largest standard dimension we get 6.5 " stroke. This does not necessarily mean that the entire stroke length will be used. It may be limited (if required) with the help of limit switches. 


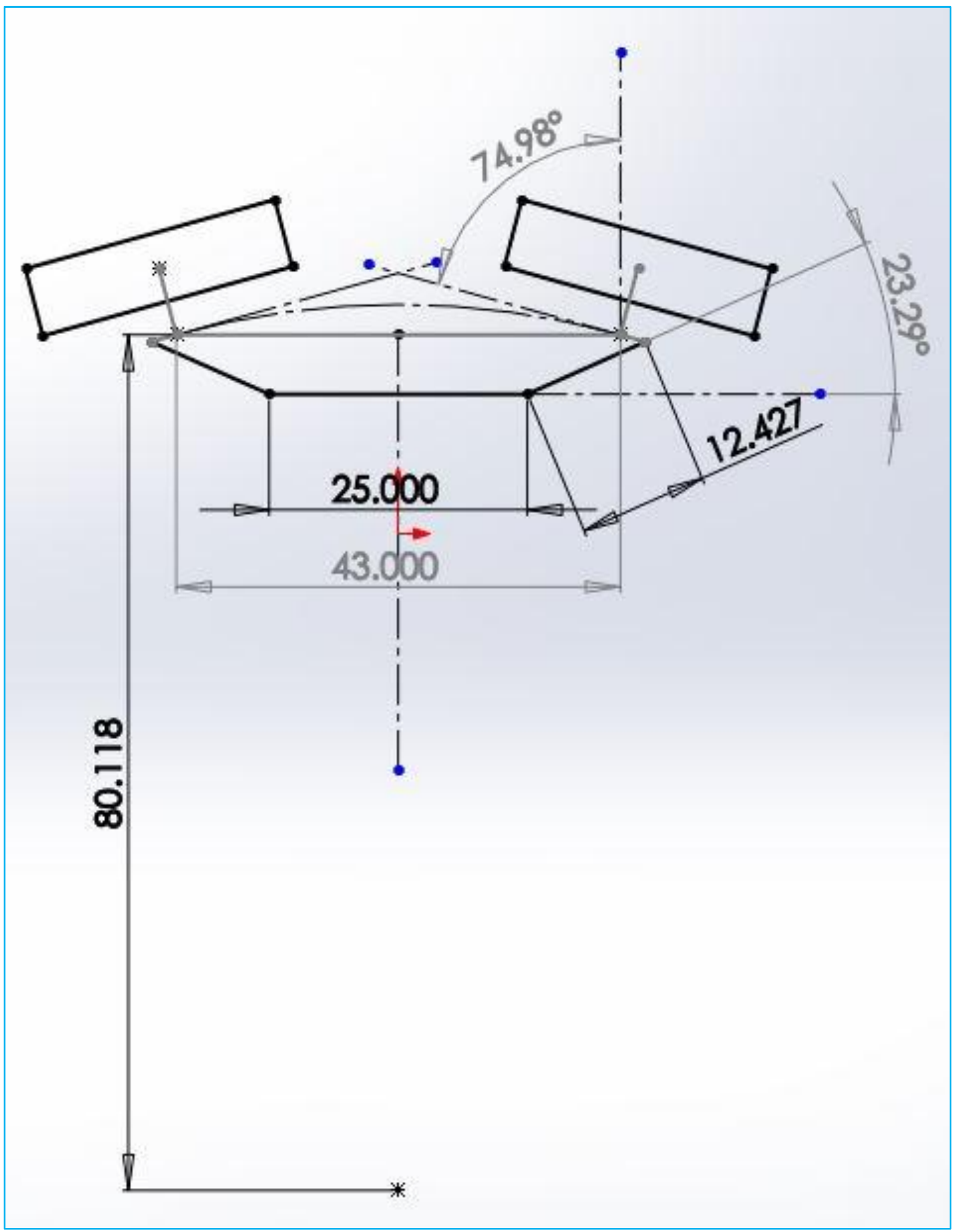

Fig -9: Zero Turning Geometry (All dimensions in inches) 
The rod used here is same as that used in the steering actuator. Thus stress based analysis will not change.

Considering Wheel Track $=56$ inch (front wheels)

Length of the double acting Steering actuator (end to end) $=$ $(4 *$ stroke length $)+(2 *$ connector length $)+$ (width of piston)

$\therefore$ Total length $=(4 * 6)+(2 * 2.5)+1 \ldots$ (in the diagram above, we have neglected the connectors)

$\therefore$ Total length $=30$ inch

King Pin to King Pin distance $=$ Wheel Track $-(2 *$ King Pin Eccentricity)

$\therefore$ King Pin to King Pin distance $=56-(2 * 6.5)$

$\therefore$ King Pin to King Pin distance $=43$ inch

Length of each tie rod

$=\frac{\text { kingpin to kingpin distance }- \text { length of steering actuator }}{2}$

$\therefore$ Length of each tie rod $=\frac{43-30}{2}$

$\therefore$ Length of each tie rod $=6.5$ inch

Let the stroke length be equal length of the tie rod $=6.5$ inch Total swept volume during zero turning $=2 *($ cylinder area $*$ swept volume)

$\therefore$ Total swept volume $=7.96$ in $^{3}$

Flow demand during zero turning mode

$$
=\frac{\text { Total swept volume } * 60}{231}
$$

$\therefore$ Flow demand during zero turning mode $=\frac{7.96 * 60}{231}$

$\therefore$ Flow demand during zero turning mode $=2.06 \mathrm{gpm}$

Power demand during zero turning mode

$$
=\frac{\text { Total flow } * \text { Pressure }}{1714}
$$

$\therefore$ Power demand during zero turning mode

$$
=\frac{2.06 * 1000}{1714}
$$

$\therefore$ Power demand during zero turning mode $=1.2 \mathrm{hp}$ (or $0.9 \mathrm{~kW}$ )

\subsection{Cylinder Design (Assuming Thin Cylinder):}

[6] Internal Pressure $(\mathrm{Pi})=1000 \mathrm{PSI}$ (or $6.895 \mathrm{~N} / \mathrm{mm}^{2}$ )

Bore Diameter $(\mathrm{di})=1.085$ inch $($ or $27.55 \mathrm{~mm})$ (same as steering actuator)

Allowable Stress $(\sigma \mathrm{t})=150 \mathrm{~N} / \mathrm{mm}^{2}$ (same material as rod) Joint efficiency $(\eta)=0.5$

Corrosion Allowance $(\mathrm{CA})=3 \mathrm{~mm}$

$\therefore$ Cylinder Wall thickness $(t)=\frac{P i * d i}{2 * \sigma \mathrm{t} * \eta}+C A$

$\therefore$ Cylinder Wall thickness $(t)=\frac{6.895 * 27.55}{2 * 150 * 0.5}+3$

$\therefore$ Cylinder Wall thickness $(t)=4.266 \mathrm{~mm} \quad$ or $5 \mathrm{~mm}$ (rounding up)

Therefore the cylinder wall should be $5 \mathrm{~mm}$ thick including corrosion allowance.

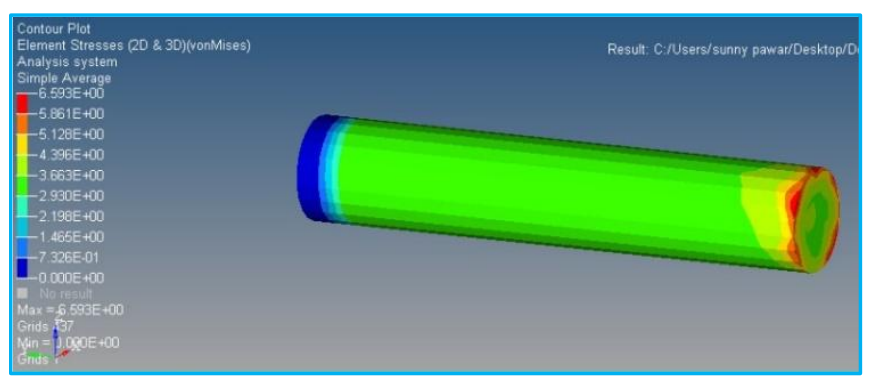

Fig -10: Strength Based Analysis of Hydraulic Tie Rod (Maximum Stress: $6.593 \mathrm{~N} / \mathrm{mm}^{2}$ )

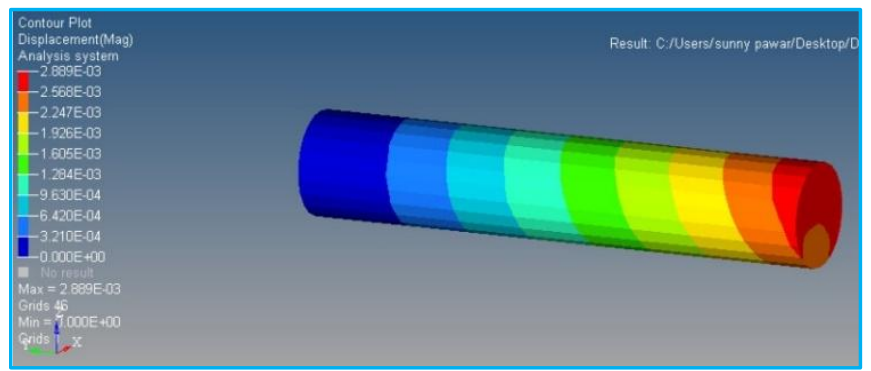

Fig -11: Strength Based Analysis of Hydraulic Tie Rod (Maximum Deflection: $2.889 \times 10^{-3}$ )

Since the maximum stress induced in the $\operatorname{rod}\left(6.593 \mathrm{~N} / \mathrm{mm}^{2}\right)$ is less than the permissible stress $\left(150 \mathrm{~N} / \mathrm{mm}^{2}\right)$, design is safe.

The deflection found from the strength based analysis shows that the rod is subjected to a deflection to the order of $10^{-3}$ $\mathrm{mm}$ which is negligible. 


\section{HST SIZING}

Table -1: Table of Constants considered for HST Calculations

\begin{tabular}{|l|l|l|}
\hline Sr. no. & Parameter & Value \\
\hline 1 & Mass of Vehicle & $2290 \mathrm{~kg}$ \\
\hline 2 & $\begin{array}{l}\text { Coef. of Drag } \\
\text { Resistance }\end{array}$ & 0.7 \\
\hline 3 & $\begin{array}{l}\text { Coef. of Rolling } \\
\text { Resistance }\end{array}$ & 0.05 \\
\hline 4 & Density of Air & $1.225 \mathrm{~kg} / \mathrm{m}^{3}$ \\
\hline 5 & Frontal Area & $1.3676 \mathrm{~m}^{2}$ \\
\hline 6 & $\begin{array}{l}\text { Relief Valve } \\
\text { Pressure }\end{array}$ & $4500 \mathrm{PSI}$ \\
\hline 7 & $\begin{array}{l}\text { Vehicle Top } \\
\text { Speed }\end{array}$ & $70 \mathrm{kmph}$ \\
\hline 8 & $\begin{array}{l}\text { Drive Wheel } \\
\text { Radius }\end{array}$ & $0.635 \mathrm{~m}$ \\
\hline 9 & $\begin{array}{l}\text { Engine Max. } \\
\text { Speed }\end{array}$ & $2400 \mathrm{rpm}$ \\
\hline 10 & $\begin{array}{l}\text { Engine Power at } \\
\text { rated max. speed }\end{array}$ & $48.471 \mathrm{~kW}$ \\
\hline
\end{tabular}

\subsection{Sizing Calculations:}

[1]

Prop-shaft (motor output shaft) rpm when vehicle speed is $70 \mathrm{kmph}$ is given by: $=\frac{\text { Vehicle speed } * 60}{\text { Wheel radius } * 3.6 * 2 \pi}$

$=\frac{70 * 60}{0.635 * 3.62 \pi}$

$=292.41 \mathrm{rpm}$

Theoretical size of motor is set to $6.858 \mathrm{in}^{3} / \mathrm{rev}$ (or 118.01 cc)

Motor efficiency is $90 \%$

$\therefore$ Actual motor size $=\frac{\text { Theoritical size }}{\text { efficiency }}$

$=\frac{6.858}{0.9}$

$=7.62 \mathrm{in}^{3} / \mathrm{rev}($ or $124.892 \mathrm{cc})$

Flow demanded by motors $=$

$2 * \frac{\text { Actual motor size *props haft rpm }}{231 * \text { motor efficiency }}$

$=2 * \frac{7.62 * 292.41}{231 * 0.9}$

$=21.434 \mathrm{gpm}$

Total flow demand $=$ flow demand by motors + flow to steering actuator

Total flow demand from pump $=21.34+1.91$

Total flow from pump $=23.34 \mathrm{gpm}$

Theoretical displacement of pump = Flow Demand by motor $* 231$ Engine Speed $\therefore$ Theoretical displacement of pump $=\frac{23.34 * 231}{2400}=2.246$ in $^{3} /$ rev

$\therefore$ Actual displacement of pump $=\frac{2.246}{0.9}=2.496 \mathrm{in}^{3} / \mathrm{rev}$

Power demanded by pump = Flow demanded by motor *relief pressure

$=\frac{23.34 * 4500}{1714}$

$=61.29 \mathrm{hp}($ or $45.704 \mathrm{~kW})$

Power demand by motor $=$

$2 *$ Relief pressure *Actual motor size *props haft rpm

$=2 * \frac{4500 * 7.62 * 292.41}{2 \pi * 63025}$

$=50.64 \mathrm{hp}($ or $37.7818 \mathrm{~kW})$

Torque from motor $=\frac{\text { relief pressure } * \text { actual motor size }}{2 \pi}$ $=\frac{4500 * 7.62}{2 \pi}$

$=5460.19 \mathrm{lb}-\mathrm{in}($ or $617.002 \mathrm{Nm})$

Torque at wheel $=$ Torque from motor $=5460.19 \mathrm{lb}$-in (or 617.002 Nm)

\subsection{Sizing Summary}

Table -2: Hydraulic Pump Sizing

\begin{tabular}{|l|l|l|l|}
\hline $\begin{array}{l}\text { AXIAL PISTON } \\
\text { PUMP }\end{array}$ & \multicolumn{2}{|l|}{ EATON HEAVY DUTY - } \\
MODEL 46 & in $/ \mathrm{rev}$ \\
\hline Displacement min. & VD & 2.49 & $\mathrm{in}^{3} / \mathrm{rev}$ \\
\hline Displacement max. & VD & 1.32 & $\%$ \\
\hline $\begin{array}{l}\text { Volumetric } \\
\text { Efficiency }\end{array}$ & $\eta_{\mathrm{pv}}$ & 90.00 & \\
\hline
\end{tabular}

Table -3: Hydraulic Motor Sizing

\begin{tabular}{|l|l|l|l|}
\hline $\begin{array}{l}\text { AXIAL PISTON } \\
\text { MOTOR }\end{array}$ & \multicolumn{2}{|l|}{ EATON HEAVY DUTY - } \\
MODEL 76
\end{tabular}

System Pressure: 4500 PSI

Inertia of Vehicle: $6000 \mathrm{kgm}^{2}$

Inertia of Motors: $40.214 \mathrm{kgm}^{2}$

\section{HST CALCULATIONS}

$[4,5]$ Now engine is coupled to pump in this system. Assuming there are no losses

$\therefore$ Engine speed $=$ Pump speed

$\therefore$ When engine speed is $1200 \mathrm{rpm}$

Pump speed $=1200 \mathrm{rpm}$

$\therefore$ Flow by pump QTH $=\frac{\text { pump rpm } * \text { pump displacement }}{231}$ 
$=\frac{1200 * 2.49}{231}$

$=12.969 \mathrm{gpm}$

Flow

in

$1 \quad$ motor

$\frac{(\text { pump disc harge } * \text { pump efficiency })-(\text { discharge for hydraulic steering })}{2}$

$=\frac{12.969-1.91}{2}$

$=5.525 \mathrm{gpm}$

Motor output speed $=\frac{\text { flow in motor } * 231}{\text { displacement of motor }}$

$$
\begin{aligned}
& =\frac{5.525 * 231}{8} \\
& =159.23 \mathrm{rpm}
\end{aligned}
$$

Motor angular velocity $=\frac{2 \pi N}{60}$

$$
\begin{aligned}
& =\frac{2 \pi * 159.23}{60} \\
& =16.67 \mathrm{rad} / \mathrm{s}
\end{aligned}
$$

Motor torque $=\frac{\text { system pressure } * \text { motor displac ement } * 0.113}{2 \pi}$

$=\frac{4500 * 7.62 * 0.113}{2 \pi}$

$=617.0015 \mathrm{Nm}$

Rolling resistance torque $=$ coefficient of rolling resistance $*$ mass of vehicle* $9.81 *$ radius of wheel

$$
\begin{aligned}
& =0.05 * 2290 * 9.81 * 0.635 \\
& =213.9781725 \mathrm{Nm}
\end{aligned}
$$

Now to calculate air drag we must know the speed of the vehicle. But since we are calculating velocity by net torque, we get an equation with unknowns on both sides.

$$
\therefore \text { Air drag torque }=\frac{\rho}{2} \mathrm{Cd} \mathrm{AV}^{2}
$$

$\therefore$ We have calculated torque assuming velocity of motor with the following empirical relation:

$\{$ Where $\mathrm{V}=\mathrm{k} * \mathrm{~N}$, taking $\mathrm{k}=0.008\}$

Explanation:

We know when the engine is run at $2400 \mathrm{rpm}$ we want a top speed of $70 \mathrm{kmph}$.

$$
\begin{gathered}
\therefore \frac{V}{3.6}=k * N \\
\therefore k=\frac{70}{3.6 * 2400} \\
\therefore \mathrm{k}=0.008
\end{gathered}
$$

Therefore at $1200 \mathrm{rpm}$,

$$
\begin{aligned}
\therefore \mathrm{V} & =0.008 * 1200 \\
& =9.6 \mathrm{~m} / \mathrm{s}
\end{aligned}
$$

$\therefore$ Air drag torque $=\frac{1.225}{2} * 0.7 * 1.3676 * 9.62 * 0.635$

$\therefore$ Air drag torque $=34.13 \mathrm{Nm}$ $\therefore$ Load torque $=$ Rolling resistance torque + Air drag torque

$$
\begin{aligned}
& =213.9781725+34.13 \\
& =248.29 \mathrm{Nm}
\end{aligned}
$$

To find actual motor torque under loading condition

$$
\mathrm{T}_{\mathrm{M}^{-}}-\mathrm{T}_{\mathrm{Load}}=[\mathrm{Iv}+\operatorname{Im}] \frac{(\omega 2-\omega 1)}{(t 2-t 1)}
$$

Where;

$\mathrm{T}_{\mathrm{M}}=$ motor torque

$\mathrm{T}_{\text {Load }}=$ Load torque

Iv = inertia of vehicle

Im = inertia of motor

$\omega 2$ = final angular velocity

$\omega 1=$ initial angular velocity

$$
\begin{gathered}
\mathrm{T}_{\mathrm{M}}-\mathrm{T}_{\text {Load }}=[\mathrm{Iv}+\mathrm{Im}] \frac{(\omega 2-\omega 1)}{(t 2-t 1)} \\
\omega 2=\frac{\{\mathrm{TM}-\mathrm{TLoad}\}\{t 2-t 1\}}{[\mathrm{Iv}+\mathrm{Im}]}+\omega 1 \\
\omega 2=\frac{[617.0015-(248.29)] * 0.5}{[6000+40.214]}+13.89 \\
\omega 2=13.89 \mathrm{rad} / \mathrm{s}
\end{gathered}
$$

$\omega 2=$ actual motor angular velocity under loading condition

Power motor $=$ Tmotor $* \omega 2$

$\therefore$ Tmotor $=\frac{37.7818 * 1000}{13.89}$

$\therefore$ Tmotor $=2719.39 \mathrm{Nm}$

$\therefore$ Net torque at wheels $=$ Actual motor torque - Load torque

$$
\begin{aligned}
& =2717.42-248.29 \\
& =2469.126 \mathrm{Nm}
\end{aligned}
$$

$$
\begin{aligned}
\text { Actual motor speed } & =\frac{\omega 2 * 60}{2 \pi} \\
& =\frac{13.89 * 60}{2 \pi} \\
& =132.73 \mathrm{rpm}
\end{aligned}
$$

$\therefore$ Angular velocity of wheel $=\frac{2 * \pi * \mathrm{~N}}{60}$

$\therefore$ Angular velocity of wheel $=\frac{2 * \pi * 132.73}{60}$

$\therefore$ Angular velocity of wheel $=13.89 \mathrm{rad} / \mathrm{sec}$

$\therefore$ Road velocity $=$ Radius of wheel $*$ angular velocity of wheel*3.6

$$
\begin{aligned}
& =0.635 * 13.89 * 3.6 \\
& =31.76 \mathrm{kmph}
\end{aligned}
$$

$$
\begin{aligned}
\text { Angular acceleration } & =\frac{\text { Net torque }}{\text { Total Inertia }} \\
& =\frac{2471.10}{6000+40.214} \\
& =0.409 \mathrm{rad} / \mathrm{s}^{2}
\end{aligned}
$$


Linear acceleration $=$ angular acceleration $*$ radius of wheel

$$
\begin{aligned}
& =0.409 * 0.635 \\
& =0.2597 \mathrm{~m} / \mathrm{s}^{2}
\end{aligned}
$$

Grade ability:

$$
\begin{gathered}
\text { Wsin } \theta=\text { Net torque } / \text { Radius of Wheel } \\
\sin \theta=\frac{1}{W}[\text { Net torque } / \text { Radius of Wheel }] \\
\sin \theta=\frac{1}{2290 * 9.81}[2471.1 / 0.635] \\
\theta=9.975^{\circ}
\end{gathered}
$$

$$
\begin{aligned}
\% \text { Grade-ability } & =\frac{\theta}{45} * 100 \\
& =\frac{9.975}{45} * 1006 \\
& =22.16 \%
\end{aligned}
$$

Similarly the calculation is repeated for engine speeds of $1500,1800,2000,2100,2200,2300 \& 2400 \mathrm{rpm}$. The entire calculation has been done on Ms Excel and the following graphs have been made to chart out the HST system's performance:

\section{HST SIMULATION}

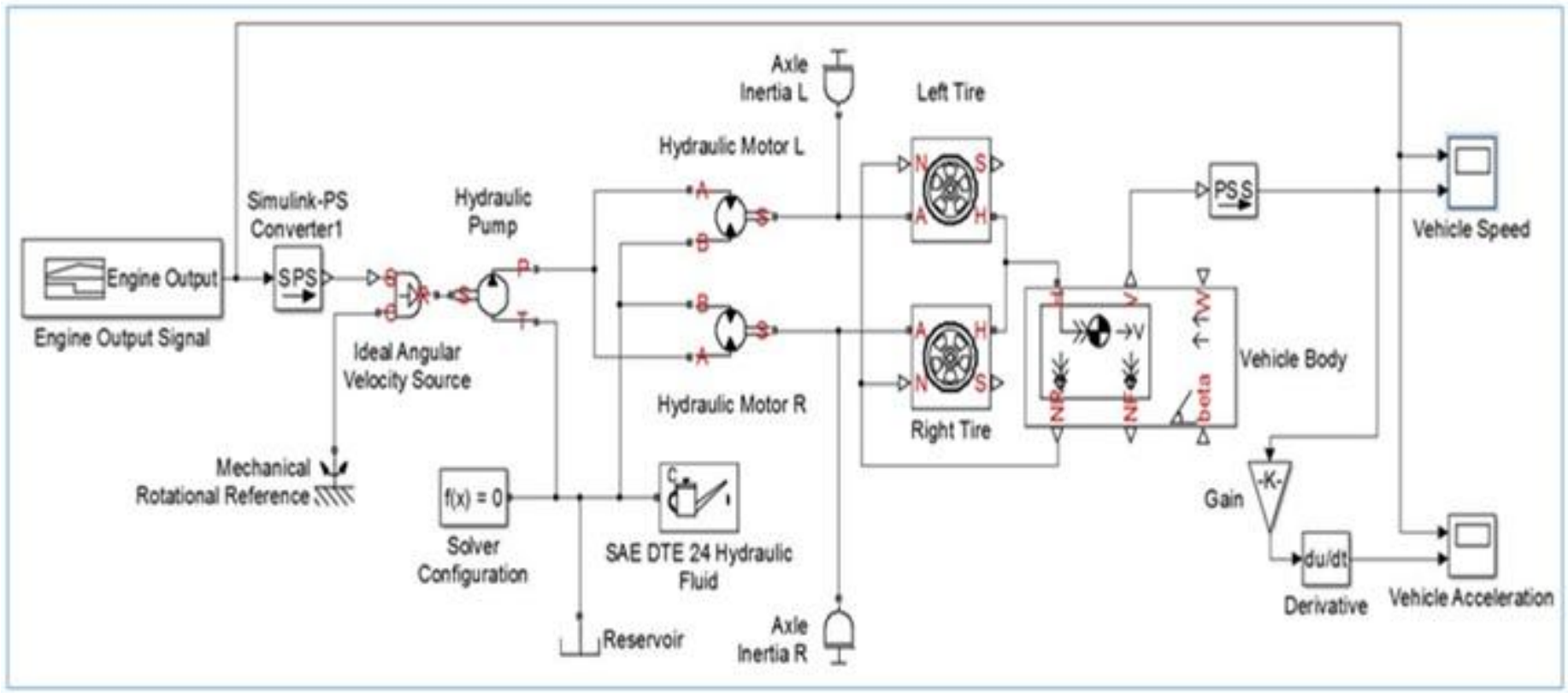

Fig -12: SIMULINK Circuit of HST System

\subsection{Simulink Circuit Component Description [10]}

Engine Input Signal block: This is a signal of engine output speed (rpm) v/s time (seconds). It simulated the engine output that is fed to the pump.

Simulink-PS Converter block: Converts the dimensionless Simulink input signal to a Physical Signal.

Rotational Coupling block: A rotational coupling has been used to couple the engine with the pump. The rotational coupling is basically used to couple mechanical component and hydraulic and hence it has been used in our circuit wherever required.

Ideal Angular Velocity Source: The block represents an ideal source of angular velocity that generates velocity differential at its terminals proportional to the physical input signal. The source is ideal in a sense that it is assumed to be powerful enough to maintain specified velocity regardless of the torque exerted on the system.
Hydraulic Pump: We have selected a uni-directional, hydraulic pump in our simulation.

The three ports of the pump are:

$\mathrm{S}$ port - it is the suction port of the pump which is connected to the engine output via the rotational coupling.

$\mathrm{T}$ port - this port is connected to the reservoir.

$\mathrm{P}$ port - this port is connected to the Directional control Valve.

Hydraulic Fluid block: This block represents the type of fluid used and helps in simulating its properties in the circuit.

Hydraulic fluid used is SAE DTE 24 in our actual solution. Although in Simulink we have used an oil of SAE 30 grade because of the similarity in properties of the two oils \& the unavailability of SAE DTE 24 in the software. 
Solver Block: A Solver block has been added to the circuit to provide global information and provide parameters so that simulation can start.

Hydraulic Reference block: This block simulated the reservoir as we have design our system as an open circuit.

Pressure Relief Valve: A Pressure Relief Valve is employed in the circuit to relieve any excess pressure in the circuit.

Hydraulic Motor: Two bi-directional hydraulic motor is used in our design. These hydraulic motor blocks are used to represent the independent left and right motors in Simulink.

Drive shaft Inertia block: It is connected to the output coming from the motors to simulate the rotational inertia of the drive shaft.

Tire blocks ( $\mathbf{L} \& \mathbf{R})$ : The tire blocks are used to simulate the tire size as it reflects upon the on road velocity.

Vehicle Body block: The vehicle body block includes parameters such as vehicle weight, air drag, etc. It is used to create a realistic simulation of the actual tractor.

Velocity Scope: This scope is connected to the output of the vehicle body block. It is used to generate the output graph of road velocity v/s time.

Gain: This block has been connected because the velocity signal is in terms of $\mathrm{kmph}$ but we want acceleration in $\mathrm{m} / \mathrm{s}^{2}$, so it multiplies the velocity signal by a factor of (1000/3600).

Derivative block: This block derives the output velocity of the vehicle dynamics block and generated an acceleration $\mathrm{v} / \mathrm{s}$ time signal.
Acceleration Scope: This Scope is connected to the output from the derivative block so as to produce an acceleration v/s time plot.

\subsection{Comparison of SIMULINK Graphs \& Excel}

\section{Graphs:}

Although the graphs may be similar in nature there are some noticeable differences. The SIMULINK graphs are based on a real-time simulation which takes into consideration various parameters such as fluid properties, miscellaneous losses, efficiency of almost all components, etc., whereas in Ms Excel we have only considered pump and motor mechanical efficiency.

Thus the graphs generated by SIMULINK are more realistic in nature however it would be very difficult to describe the behaviour as compared to the graphs generated by Excel. The SIMULINK circuit also factors in the hydraulic fluid properties, shaft inertias, as well as pressure relief valve settings which have been neglected in the Excel calculations.

The acceleration curve especially may tend to vary, as in excel we have had to assume the velocity when calculating air drag torque. These assumptions based on hit \& trial may give rise to error in the nature of the acceleration curve.

It should also be noted that the acceleration in the excel sheets is calculated based on torque and inertia which are found based on assumptions however in Simulink the acceleration is found by derivation of the velocity output for the same time interval. Thus the Simulink graphs have a higher degree of accuracy.

For the purpose of evaluating the accuracy of the Excel graphs we have calculated the Normalized Root Mean Square Deviation with respect to the SIMULINK graphs, for both (velocity \& acceleration). 


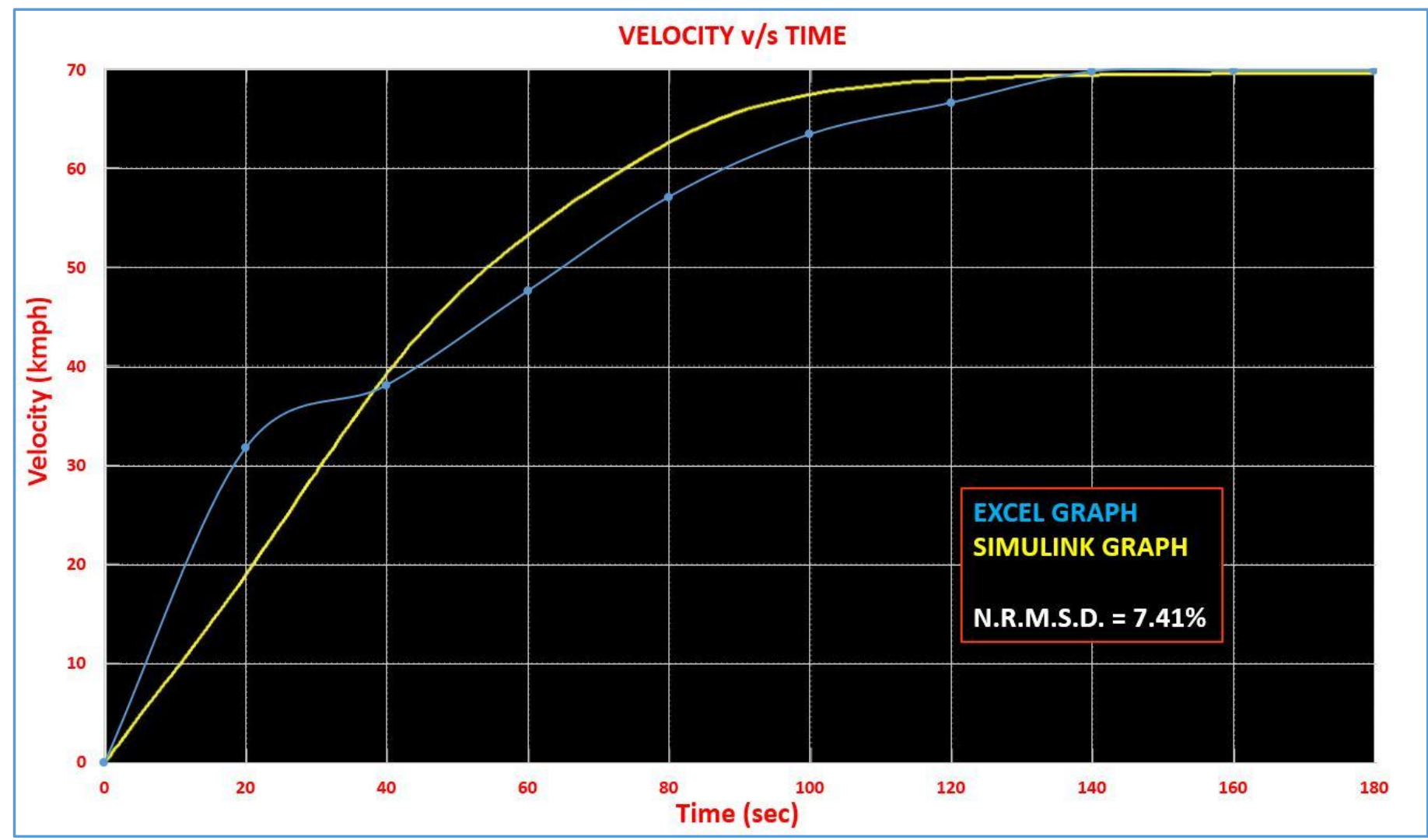

Graph -2: Simulink v/s Excel (Velocity v/s Time)

Table -4: Simulink v/s Excel (Velocity v/s Time)

\begin{tabular}{|c|c|c|c|c|}
\hline \multicolumn{5}{|c|}{ SIMULINK v/s EXCEL (VELOCITY v/s TIME) } \\
\hline Sr. No. & Time & $\begin{array}{c}\text { Simulink } \\
\left(\mathrm{y}_{1}\right)\end{array}$ & $\begin{array}{c}\text { Ms Excel } \\
\left(\mathrm{y}_{2}\right)\end{array}$ & $\begin{array}{c}\text { Sq. } \\
\text { Difference }\end{array}$ \\
\hline 1 & 0 & 0.0 & 0.0 & 0.00 \\
\hline 2 & 20 & 19.0 & 32.0 & 169.00 \\
\hline 3 & 40 & 39.0 & 38.0 & 1.00 \\
\hline 4 & 60 & 54.0 & 48.0 & 36.00 \\
\hline 5 & 80 & 63.0 & 57.0 & 36.00 \\
\hline 6 & 100 & 67.5 & 64.0 & 12.25 \\
\hline 7 & 120 & 68.5 & 66.5 & 4.00 \\
\hline 8 & 140 & 69.0 & 70.0 & 1.00 \\
\hline 9 & 160 & 69.0 & 70.0 & 1.00 \\
\hline 10 & 180 & 69.0 & 70.0 & 1.00 \\
\hline $\mathrm{n}=$ & 10 & \multicolumn{5}{|c|}{ Total Sq. Diff: } & 261.25 \\
\hline
\end{tabular}

Square Difference $=(\mathrm{y} 1-\mathrm{y} 2)^{2}$

Total Sq. Difference $=\sum_{i=1}^{n}($ Sq. Difference $)$

Mean Sq. Difference $=\frac{\text { Total Sq. Difference }}{\mathrm{n}}$

$=26.125$

$$
\therefore \text { Mean Sq. Difference }=\frac{261.25}{10}
$$

Root Mean Sq. Difference $=\sqrt{\text { Mean Sq. Difference }}$

$\therefore$ Root Mean Sq. Difference $=\sqrt{26.125}$

$$
=5.11 \mathrm{kmph}
$$

Normalised Root Mean Sq. Deviation $=$ $\frac{\mathrm{RMSD}}{\mathrm{y} 1 \mathrm{max}-\mathrm{y} 1 \mathrm{~min}} * 100 \%$

$\therefore$ Normalised Root Mean Sq. Deviation $=\frac{5.11}{69-0} * 100 \%$ $=7.41 \%$

Since the NRMSD is less than $10 \%$, it is within acceptable limits. 


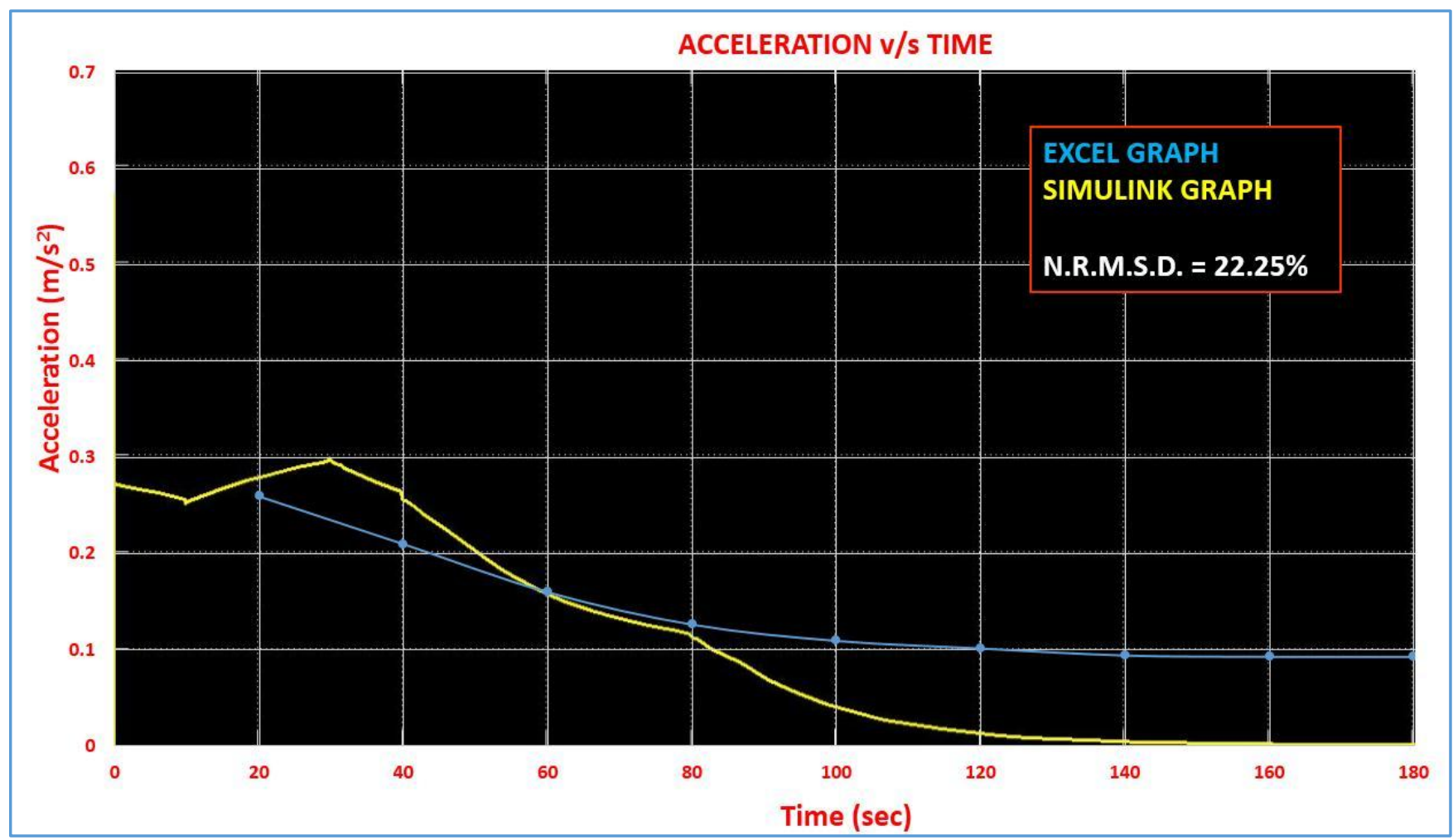

Graph -3: Simulink v/s Excel (Acceleration v/s Time)

Table -5: Simulink v/s Excel (Acceleration v/s Time)

\begin{tabular}{|c|c|c|c|c|}
\hline \multicolumn{5}{|c|}{ SIMULINK v/s EXCEL (ACCELERATION v/s TIME) } \\
\hline $\begin{array}{c}\text { Sr. } \\
\text { No. }\end{array}$ & Time & $\begin{array}{c}\text { Simulink } \\
\left(\mathrm{y}_{1}\right)\end{array}$ & $\begin{array}{c}\text { Ms Excel } \\
\left(\mathrm{y}_{2}\right)\end{array}$ & $\begin{array}{c}\text { Sq. } \\
\text { Difference }\end{array}$ \\
\hline 1 & 0 & 0.270 & 0.300 & 0.0009 \\
\hline 2 & 20 & 0.285 & 0.260 & 0.000625 \\
\hline 3 & 40 & 0.265 & 0.210 & 0.003025 \\
\hline 4 & 60 & 0.160 & 0.160 & 0.00 \\
\hline 5 & 80 & 0.120 & 0.130 & 0.0001 \\
\hline 6 & 100 & 0.040 & 0.110 & 0.0049 \\
\hline 7 & 120 & 0.015 & 0.100 & 0.007225 \\
\hline 8 & 140 & 0.005 & 0.090 & 0.007225 \\
\hline 9 & 160 & 0.000 & 0.090 & 0.0081 \\
\hline 10 & 180 & 0.000 & 0.090 & 0.0081 \\
\hline $\mathrm{n}=$ & 10 & \multicolumn{5}{|c|}{ Total Sq. Diff: } & 0.0402 \\
\hline
\end{tabular}

Square Difference $=(y 1-y 2)^{2}$

Total Sq. Difference $=\sum_{i=1}^{n}$ (Sq. Difference $)$

Mean Sq. Difference $=\frac{\text { Total Sq. Difference }}{\mathrm{n}}$

$\therefore$ Mean Sq. Difference $=\frac{0.0402}{10}$

$$
=0.00402
$$

Root Mean Sq. Difference $=\sqrt{\text { Mean Sq. Difference }}$

$\therefore$ Root Mean Sq. Difference $=\sqrt{0.00402}$

$$
=0.0634 \mathrm{~m} / \mathrm{s}^{2}
$$

Normalised Root Mean Sq. Deviation $=$ $\frac{\text { RMSD }}{\mathrm{y} 1 \mathrm{max}-\mathrm{y} 1 \mathrm{~min}} * 100 \%$

$\therefore$ Normalised Root Mean Sq. Deviation $=\frac{0.0634}{0.285-0.0} * 100 \%$

$=22.25 \%$

$22.25 \%$ NRMSD may be due to the extra parameters being considered in SIMULINK. It may also be caused due the difference in the methods used to calculate acceleration. 


\section{COST EFFECTIVENESS}

Table -6: Sample cost report

\begin{tabular}{|c|c|c|c|c|}
\hline \multicolumn{5}{|c|}{ COST REPORT } \\
\hline \multicolumn{5}{|c|}{ PURCHASE ORDER FOR HYDRAULIC CIRCUIT COMPONENTS } \\
\hline Sr. No. & Description & Qty. & Unit Cost & Total Cost \\
\hline & & & INR & INR \\
\hline 1 & Eaton Heavy Duty Axial Piston Pump Model 46 & 1 & 14000 & 14000 \\
\hline 2 & Eaton Heavy Duty Axial Piston Motor Model 76 & 2 & 14000 & 28000 \\
\hline 3 & Direction Control Valve $(D C V)$ & 3 & 2000 & 6000 \\
\hline 4 & DCV Control Lever Mechanism & 3 & 1200 & 3600 \\
\hline 5 & Reservoir & 1 & 6000 & 6000 \\
\hline 6 & Hoses & 24 & 300 & 7200 \\
\hline $7 !$ & Steering Actuator (Double Acting Cylinder) & 1 & 6500 & 6500 \\
\hline 8 & Hydraulic Tie rods & 2 & 3250 & 6500 \\
\hline $9 !$ & PSU (Char-Lynn series 2) & 1 & 6000 & 6000 \\
\hline 10 & Hydraulic Fluid (1L) & 21 & 250 & 5250 \\
\hline 11 & Pressure Relief Valves & 4 & 1500 & 6000 \\
\hline 12 & Flow Compensator & 1 & 1500 & 1500 \\
\hline 13 & Manifolds & 7 & 500 & 3500 \\
\hline & & GR & TOTAL (INR) & 100050 \\
\hline
\end{tabular}

! Need not be considered

The above cost report includes the steering actuator as well as PSU. These components are already present in the baseline vehicle thus need not be considered. The reason we have included them is because details for the same weren't provided and so we have had to design our own power steering system for this baseline vehicle.

Thus if we neglect the cost of the steering actuator as well as the PSU the cost reduces to: 87550 Indian Rupees.

This cost is inclusive of not only the main components like motors and pump but also the hoses, fluid, DCVs \& the PRVs.

The number of manifolds is taken considering one manifold for each DCV and PCV. If the manifolds can be combined or reduced in number it can further reduce the cost.
The components used in this solution are used as replacements to the gear box, differential \& braking system. In other words the need of the gear box, differential and braking system is eliminated. Thus the cost of these three systems can be further deducted from the overall vehicle cost.

Therefore, the overall cost of the vehicle can be calculated as:

\section{Overall Cost $=$ Cost of Baseline Vehicle $-\{$ Cost of Gear Box, Differential \& Braking system $\}+87550$ INR}

NOTE: Braking system includes brake mechanism as well as the brake pedals, shafts, and any related mounting accessories. 


\section{ERGONOMICS}

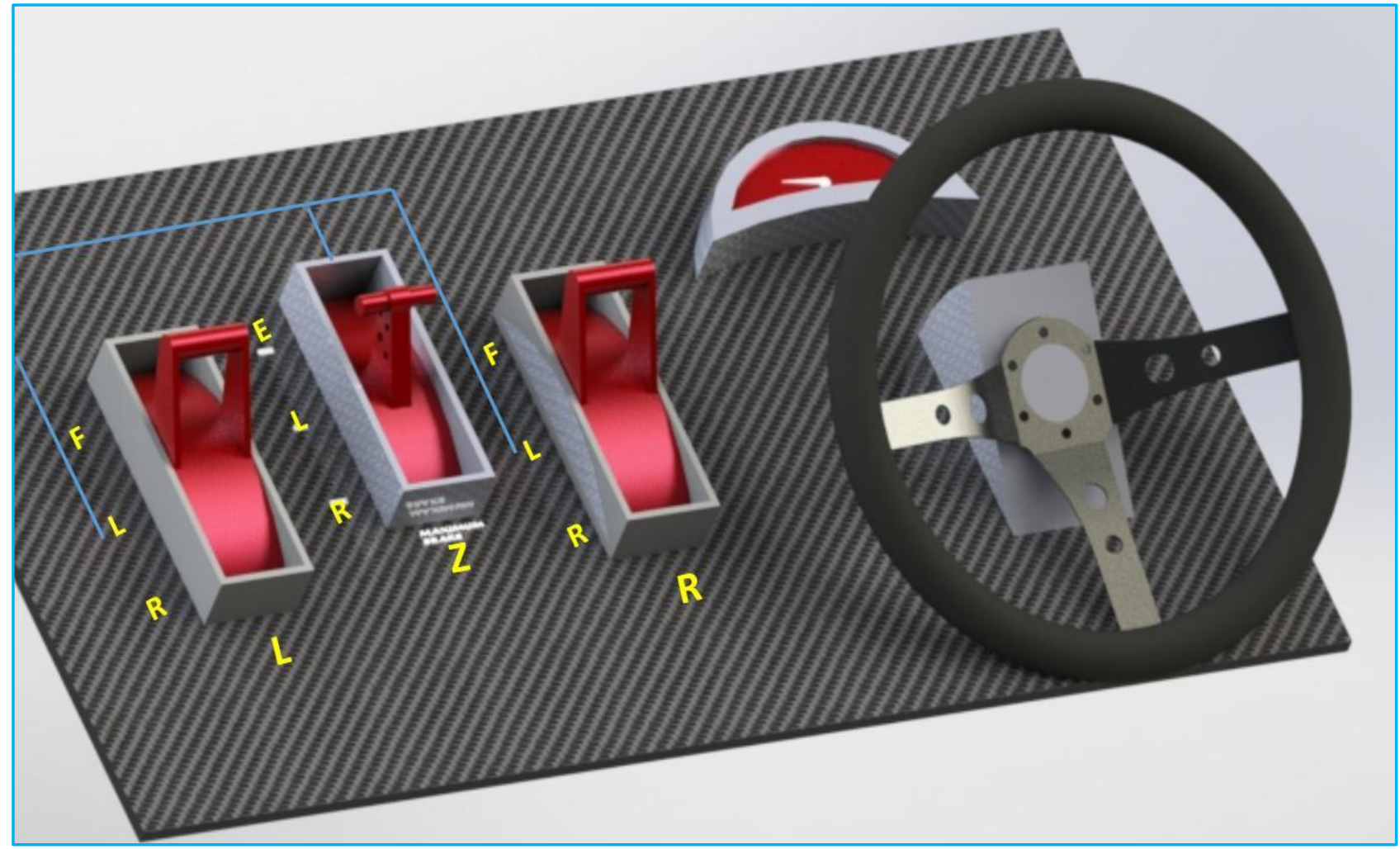

Fig -13: Ergonomics of Control Panel

Since we are not using a gear box, the vehicle will not require a gear shifter or a clutch pedal. The vehicle will operate similar to a CVT driven vehicle, with simply one accelerator pedal. Since the conventional braking system is eliminated, the vehicle will not require the brake pedals. The braking will be achieved with the lock positions on the corresponding motor's DCV.

The dash panel will look something similar to what is seen above. There will be a steering wheel which is connected to the PSU. There will be a display which may include tachometer, speedometer, engine temperature, etc. Since in India we normally drive with the gear shifter in our left hand, we have put the $3 \mathrm{DCV}$ controls on the left hand side of the steering wheel, within easily accessible distance (or rather within the reach envelope of the driver).

The DCV's controls are broadly labelled as L, Z \& R.

$\mathrm{L}=$ controls rear left wheel's motor

$\mathrm{R}=$ controls rear right wheels motor

$\mathrm{Z}=$ this DCV is used to actuate the zero turn tie rods.

The double acting steering actuator is connected to the PSU which is controlled by the steering wheel.

The central DCV which controls the hydraulic tie rods, has its three positions labelled as E, L \& R which stand for Expand, Lock \& Retract. The L \& R DCVs have their three positions labelled as F, L \& R which stands for Forward, Lock \& Reverse.
There is a blue line shown in the figure which connects the central DCV to the lock position of the L \& R DCVs. This is a means of fool proofing. It reminds the driver that before the central lever is used, the L \& R DCVs must be in lock position. In other words the vehicle must be stationary before going into or coming out of zero turning mode. Once the wheels have turned, the central DCV should be locked and the L \& R DCV should be put into opposite positions (one in forward \& the other in reverse). Depending on which is in forward and which is in reverse the vehicle will either turn clockwise or counter-clockwise when seen from above. As a fail-safe, if the zero turn tie rods are being actuated \& at the same time the wheels are rotating the power requirement will exceed what the prime mover is capable of supplying \& thus the system will stall before tremendous forces are experienced by the tie rods and other steering system members.

\section{VALUE PROPOSITION}

\subsection{Zero Turning \& Regular Turning Operations}

If you consider zero turning as moving about a pivot point, this is achieved in our solution. The baseline vehicle has a minimum turning radius of exactly $3099 \mathrm{~mm}$ (brake assisted). This means when the front wheels are fully turned to one side (full right for example) and corresponding right brake on the right rear tire is applied. The vehicle will take the tightest possible right turn with a turning radius of 3099 $\mathrm{mm}$. This method of turning has not been eliminated in our solution. The tractor is still capable of turning in this fashion 
as seen in the diagrams on pages $6 \& 7$. In addition to this, the tractor has also been given the capability to take a zero turn about the vertical pivot axis located in the middle of the two rear wheels. The rotation of the vehicle is achieved by the rear wheels rotating in opposite directions simultaneously. The speed of rotation can be controlled by the driver. The means by which the rear wheels rotate in opposite directions is achieved in our solutions by means of hydrostatic transmission system. The baseline vehicle has a gear box and differential, which cannot enable the rear wheels to rotate in opposite directions simultaneously. The radius of turn envelope of a zero turn as seen on page 8 , is $2156 \mathrm{~mm}$. This is almost 1 meter less than what the baseline vehicle is capable of. In fact the wall to wall distance between which the vehicle can take a zero turn is actually $3377 \mathrm{~mm}$ !! As proven below:

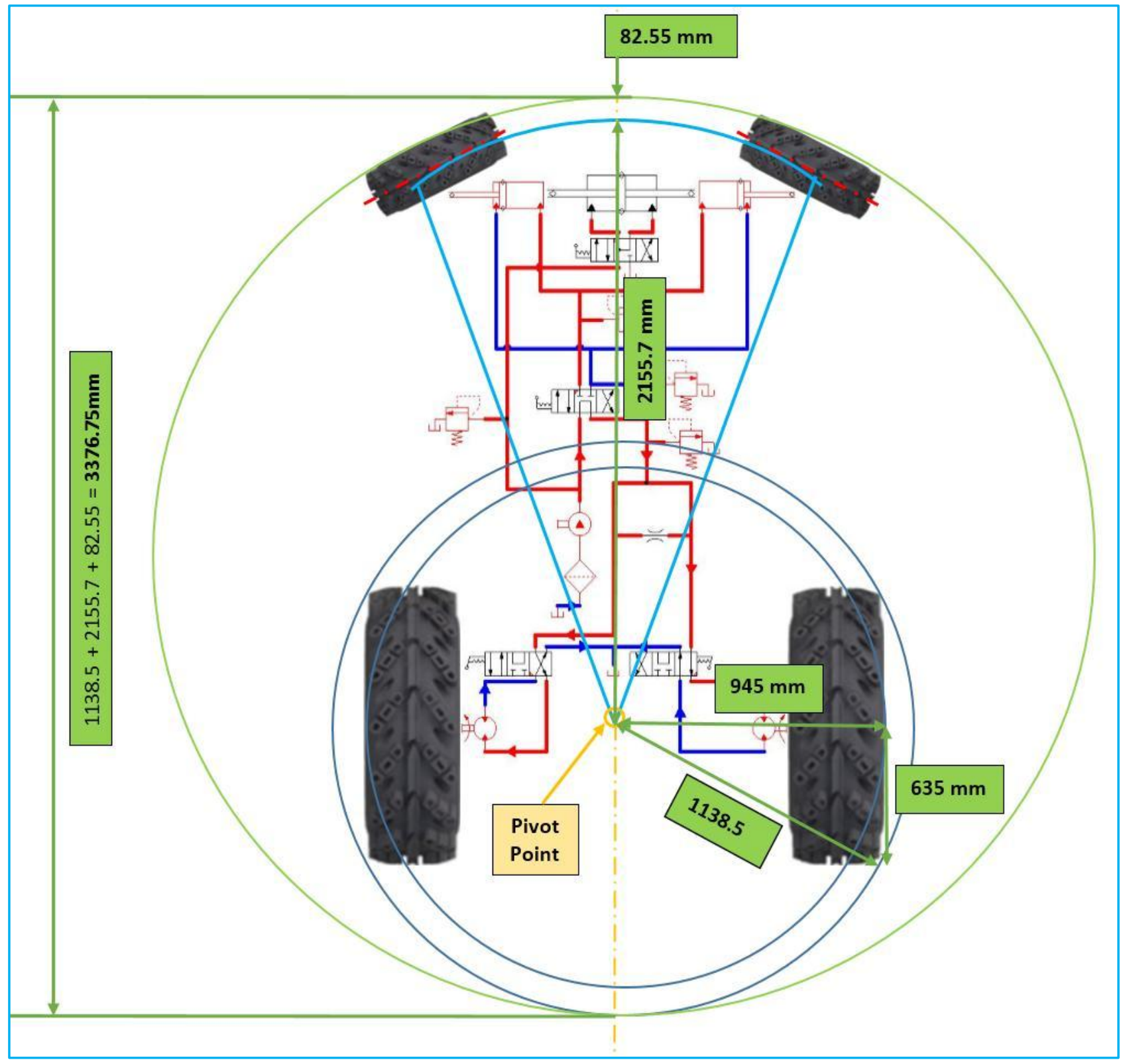

Fig -14: Wall to Wall Distance

\subsection{Transmission:}

When it comes to the transmission system, the first thing to be noticed is that we have taken a baseline vehicle which on paper has a rated top speed of $31.2 \mathrm{kmph}$ (forward) \& 24 kmph (reverse), \& by means of hydrostatic transmission we have effectively been able to make the vehicle run at 70 $\mathrm{kmph}$. Since the transmission is of hydrostatic type, it gives symmetrical performance in forward as well as reverse.
Thus the top speed in forward as well as in reverse is close to $70 \mathrm{kmph}$. We have done this because in India we often find tractors having to cut across cities and thus creating traffic problems due to their width (making it difficult to overtake on narrow roads or single lane road) and slow speed. Thus the means of moving at $70 \mathrm{kmph}$ rather than $31.2 \mathrm{kmph}$ should solve this problem to a certain extent. 
In case the company wants to limit the speed to around 31.2 kmph then it would be possible to use a smaller pump and motor and thus even a smaller engine (lesser horse power) would suffice. Thus it would bring down the overall cost, making it more affordable for the Indian economy. It would also reduce the overall weight of the tractor.

\subsection{Finance}

In this solution we have eliminated the gear box, differential and braking system and replaced these with the hydrostatic transmission system for the reason mentioned above. Thus the cost difference would not be too much. The cost of all the parts used in the hydraulic circuit is nearly 1 lakh. However, since the baseline vehicle already comes with its own power steering circuit, this cost can be neglected making the overall change cost around 87550 Indian rupees. We must also note that since the vehicle will not require a gear box, differential and braking system as these are all included in the HST system, the cost of these systems can be further deducted from the overall cost. Thus the net cost of the vehicle with zero turning capabilities will not differ much from the cost of the existing baseline vehicle. If the cost of the gear box, differential \& braking system is more than 87550 Indian rupees, the net cost will be even less than that of the baseline vehicle.

\subsection{Troubleshooting \& Debugging}

From an engineer's point of view we have now combined the steering, braking and transmission system in the same hydraulic circuit. Any glitch in the same would not go unnoticed as:

1. A fault in any part of the circuit such as a leak would be easily noticed.

2. If there is a leak in any of the hoses, since none of the circuits are independent of one another the entire system will fail to operate making the fault easily detectable.

For example, if there is a problem in the brakes of the baseline vehicle, it will go unnoticed until the driver wishes to apply the brakes. In our solution, if there is a fault in the circuit such as a leak, not only will it affect the braking performance, but the pressure will not build up and thus the transmission will also not work effectively, making it obvious to the driver that something is wrong. It is an example of an inherent fail-safe in the hydraulic circuit.

Detecting the source of error, would also be very simple as technically there are only three parts in our hydraulic circuit:

1. Steering line

2. Zero turning line

3. HST lines (L \& R)

The serviceman or user would simply have to check these three lines and thus detecting the leak would not be a very tedious task. The chances of leaks are quite less as the hose we have selected can be used for continuous operation at pressures ranging up to 5000 PSI, whereas we have limited the pressure to 4500 PSI in our solution. Nevertheless, in case of leak or burst, the cost of a hose with its end fittings is not very expensive (as seen in the cost report) and considering mass production, the cost of such a spare part can be easily brought down.

\subsection{Serviceability}

Ideally, a designer would want to design any automobile such that the time it spends under servicing is as less as possible. This would:

1. Enable service team to repair/take care of more problems in less time.

2. Keep customers satisfied.

3. Prevent a buildup of vehicles thus reduce storage space required.

Simply put, the vehicle should be serviced as quickly as possible $\&$ the frequency of failure of components should be as less as possible.

From the cost report parts such as the motors and pump, which are costliest, are also the most reliable and may also come with a warranty period.

Other parts which have a higher tendency to fail such as hoses are much less expensive in comparison and hardly any dismantling is required to replace a hose. These can be replaced within minutes once the faulty hose is detected.

Only the actuators and manifolds (containing the DCVs \& PRVs) have to be mounted. The hoses are simply fastened into the correct holes with a wrench.

\subsection{Maintenance}

Normally in a gear box driven system one must check the oil level, occasionally drain and replace the oil etc. Same will have to be done for the engine. In our design the inspection can easily be done by opening the reservoir tank (when the vehicle is not switched on). The filters can also be checked and replaced occasionally, if required.

\subsection{Ergonomics}

In our solution we have eliminated the clutch pedal, brake pedal and gear shifter. Instead there are only 3 DCV control levers. This makes operating the tractor very simple. The tractor would operate similar to an automatic vehicle or a CVT driven vehicle. The DCV controls can either be on the left or right of the steering wheel depending on user preference. For example, in India we normally have the gear shifter on our left hand side, so in countries like India a left hand side DCV control would be easier to get used to.

\subsection{Speed to the Market}

The technology that we have used in our solution is not new by any means. It already exists and is commercially available, thus making the solution technically feasible. We have only designed a circuit using these parts so as to endow the tractor with zero turning capabilities. The actuator's mounting locations and mounting plates will have to be 
decided \& this should not consume a lot of time. This is a simple process and even preparing a prototype should not be very time consuming. Once a successful prototype is built the design can be mass produced. If we consider one week to finalize the mounting plate locations and make necessary changes (like drill holes for bolting locations), followed by 3 weeks of testing the prototype and fixing any bugs, then we could have a final design ready within one months' time.

\section{CONCLUSION}

This innovation if proven successful would definitely be a breakthrough. We highly doubt it would fail as similar concepts are commercially seen, such as the John Deere Skid Steer. The fact that the zero turning vehicle will be able to turn within a wall to wall distance of only $3377 \mathrm{~mm}$ is quite remarkable considering that the baseline vehicle has a brake assisted turning radius of $3099 \mathrm{~mm}$.

The value proposition mentioned above pertains specifically to the $5065 \mathrm{E}$ model, however the same methodology provided in our solution can be applied to any tractor or four wheeled vehicle.

We also need to consider how this would increase the speed of manufacturing or rather reduce the effort and time currently spent in the manufacturing stages. The assembly processes could be easily automated and hose connections hardly take up any time. This would also reduce time spent on quality evaluation and testing. Altogether it could possibly lead to a marginal, if not substantial, increase in production capacity as well as profit.

\section{REFERENCES}

[1]. Fluid Power with Applications, $6^{\text {th }}$ Edition, Anthony Esposito, Pearson Publication

[2]. Industrial Hydraulics Manual, $5^{\text {th }}$ Edition, $2^{\text {nd }}$ Printing, Eaton Hydraulics Training Services, Eaton Publication

[3]. SolidWorks 2010 Bible, Matt Lombard, Wiley Publication

[4]. Fundamentals of Vehicle Dynamics, Thomas D. Gillespie, Published by S.A.E., 1992

[5]. Theory of Ground Vehicles, $3^{\text {rd }}$ Edition, J. Y. Wong, John Wiley \& Sons Publication

[6]. Design of Machine Elements, $3^{\text {rd }}$ Edition, V. B. Bhandari, McGraw Hill Publication

[7]. Practical Finite Element Analysis, Nitin S. Gokhale, Sanjay S. Deshpande, Sanjeev V. Bedekar, Anand N. Thite, Finite to Infinite Publications.

[8]. Char-Lynn Hydraulics Steering Catalog, C-STOVMC001-E, Published by Eaton, 2003

[9]. Hydraguide ${ }^{T M}$ Series Hydrostatic Steering Units, Catalog No. 1560-002/US, Published by Parker Hydraulics

[10]. www.mathworks.in

[11]. www.eaton.in

[12]. www.deere.co.in

\section{BIOGRAPHIES}

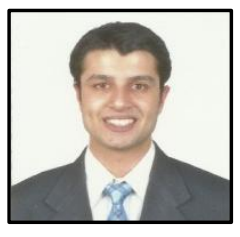

Sumair Sunny, Mechanical Engineering Graduate, M.I.T., Pune, India

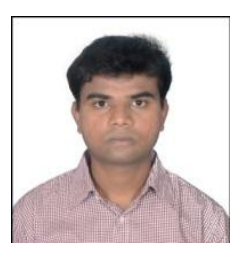

Sunny Pawar, Mechanical Engineering Graduate, M.I.T., Pune, India

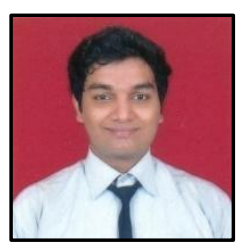

Siddhesh Ozarkar, Mechanical Engineering Graduate, M.I.T., Pune, India 